\title{
Rastros de la humanidad y la búsqueda de una sociología filosófica**
}

\author{
Simon Susen
}

\section{Introducción}

$\mathrm{E}$ 1 principal objetivo de este artículo consiste en examinar algunos temas centrales discutidos por Daniel Chernilo en su libro Debating Humanity: Towards a Philosophical Sociology (2017). Con este fin, el análisis se divide en dos partes. La primera parte brinda un breve resumen de la estructura temática del libro y presenta algunos de sus argumentos centrales. La segunda parte examina los aspectos más controvertibles y resalta sus principales limitaciones. A modo de conclusión, este artículo sostiene que el estudio de Chernilo es un importante recordatorio del hecho de que un entendimiento verdaderamente comprehensivo de la sociedad requiere un encuentro crítico con el concepto de humanidad.

\section{Argumentos clave}

El libro Debating Humanity de Chernilo es una importante contribución a la teoría social contemporánea. Allí se exploran las maneras en las que importantes académicos de la sociología y la filosofía han intentado

\footnotetext{
* Simon Susen es Profesor de Sociología en City, University of London. Es Miembro Asociado del Bauman Institute y, con Bryan S. Turner, Editor del Journal of Classical Sociology. Email: Simon.Susen@city.ac.uk

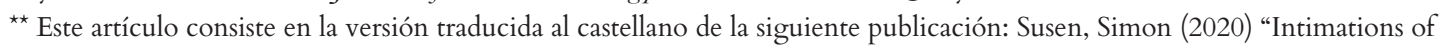
Humanity and the Case for a Philosophical Sociology", Journal of Political Power 13(1): 123-160. La traducción fue realizada por Bernardo Villegas (Pontificia Universidad Católica del Ecuador) y revisada por Sebastián Raza (University of Cambridge) y Simon Susen (City, University of London). La publicación de este artículo cuenta con la autorización del autor y del editor de la revista antes mencionada, Mark Haugaard.
} 
comprender la peculiaridad de nuestra existencia como especies, al emplear conceptos fundacionales como "humanidad", "lo humano", "seres humanos" y "naturaleza humana". El libro se enfoca en el trabajo de prominentes pensadores de finales del siglo XX e inicios del siglo XXI. Chernilo describe su tarea como una sociología filosófica ${ }^{2}$, la cual está basada en tres supuestos:

I. "Las características antropológicas que nos definen como seres humanos son en gran medida independientes de la vida social, aunque no pueden ser realizadas completamente fuera ella." En otras palabras, las características constitutivas que compartimos como miembros de la misma especie son irreductibles a las condiciones históricas variables en las que nos encontramos situados cuando nos relacionamos, interactuamos y trabajamos sobre nuestros entornos naturales y sociales. Chernilo identifica y examina siete propiedades - las que, en su opinión, son distintivamente humanas - al revisar los escritos de siete intelectuales influyentes: la autotrascendencia (Hannah Arendt), la adaptación (Talcott Parsons), la responsabilidad (Hans Joas), el lenguaje (Jürgen Habermas), las evaluaciones fuertes (Charles Taylor), la reflexividad (Margaret Archer) y la reproducción de la vida (Luc Boltanski)

II. Nuestras características distintivas como especie sirven como el fundamento más viable y confiable para la justificación de argumentos normativos - incluyendo ideas (e ideales) emancipadoras como la justicia, la dignidad, la democracia y la "buena vida". Según esta tesis, "un principio universalista de humanidad es preferible sobre concepciones particularistas de raza, cultura identidad y clase"4, en tanto los primeros trascienden las contingencias estructurales y agenciales de los últimos. En otras palabras, mientras que los intereses humanos son universalizables, 
los intereses individuales o específicos a un grupo son socialmente excluyentes.

III. Las formas simbólicas - incluyendo las ideas, ideales e ideologías - son "irreductibles a las posiciones materiales o socioculturales que los humanos ocupan en la sociedad" ${ }^{5}$. Su existencia y desarrollo se articulan en nuestra "capacidad (cognitiva) para reflexionar acerca de lo que nos hace humanos"6 - y, se podría añadir, en nuestra capacidad performativa para participar en la construcción de lo que nos define como "humanos". $\mathrm{Si}$, como miembros de una misma especie, no estuviéramos equipados con un conjunto de competencias antropológicas, no seríamos capaces de proyectarnos hacia el futuro, dejando a un lado la capacidad de vernos envueltos en prácticas de autorrealización individual y/o transformación societal. Sin estas características distintivas como especie, sería muy difícil, si no imposible, explicar la constitución normativa que permea todos los órdenes sociales.

Como indica Chernilo, el uso de la etiqueta sociología filosófica muestra que la filosofía y la sociología están íntimamente interrelacionadas. Posiblemente, esta etiqueta también sugiere que se debe dar prioridad programática a esta última. No es un accidente, entonces, que Chernilo no conciba su programa como una filosofía sociológica ${ }^{7}$, pues este concepto podría, por decirlo así, cambiar los "términos y condiciones" de su esfuerzo. El punto clave de Chernilo sobre este asunto es que sería erróneo construir una oposición artificial y contraproducente entre la sociología y la filosofía. En su opinión, las conexiones entre estas dos disciplinas han sido - y continúan siendo - reconceptualizadas en tres niveles: 
I. Desde un punto de vista positivista, el pensamiento filosófico constituye una "herencia precientífica de la sociología"8, es decir, suple la función epistémica de formar un horizonte presuposicional en el cual los investigadores de las humanidades y ciencias sociales se fundamentan para producir conocimiento basado en evidencias generadas bajo los principios del método científico. Con relación a este punto - posiblemente Comteano y Durkheimiano -, son las investigaciones orientadas empíricamente, y no las especulativas indagaciones filosóficas, lo que dominará los futuros desarrollo de las formas institucionalizadas de conocimiento humano, como lo muestran la creciente influencia de las ciencias naturales y sociales. ${ }^{9}$

II. Desde un punto de vista socio-reflexivo, el pensamiento filosófico permite - y, por lo tanto, promueve - "la autoclarificación epistemológica"10 en las ciencias sociales en general y en la sociología en particular. Siguiendo esta perspectiva, a la filosofía se le asigna un rol como "subempleado"11, más que el de un "arquitecto". En lugar de proveer hallazgos fundacionales (notablemente relacionados a preocupaciones de carácter existencial como la naturaleza del ser, del conocimiento, de la moralidad, de la lógica y de la estética), la función de la filosofía es orientacional, en el sentido de que ofrece guías sobre cómo producir herramientas epistémicas confiables y marcos de referencia en las ciencias sociales. Dicotomías paradigmáticas - como positivismo vs. interpretativismo, materialismo vs. idealismo, realismo vs. constructivismo, objetivismo vs. subjetivismo, determinismo vs. voluntarismo, colectivismo vs. individualismo, inductivismo vs. deductivismo - revelan profundas divisiones intelectuales en las ciencias sociales, las cuales, en un mayor o menor grado, se encuentran informadas por suposiciones filosóficas acerca de la naturaleza del 
ser, del conocimiento y de la lógica. Sobre este asunto - posiblemente weberiano -, es vital para los científicos sociales reflejar la relación entre sus debates teóricos (incluyendo las disputas epistemológicas) y el trabajo empírico (incluyendo la investigación basada en evidencias). ${ }^{12}$ III. Desde un punto de vista normativista, el pensamiento filosófico funciona como "una fuente desde la cual se establecen varios motivos normativos centrales"13. La filosofía se cuestiona no sólo con el modo cómo son las cosas, sino también con el modo cómo podrían y deberían ser. Este compromiso se articula especialmente en la filosofía moral, pero también, en un grado considerable, en la filosofía política y social. Una actitud normativista es prominente en versiones "críticas" de la sociología - como el marxismo ${ }^{14}$ y la teoría crítica ${ }^{15}$, pero también el feminismo ${ }^{16}$, el postcolonialismo ${ }^{17}$ y otras perspectivas explícitamente "críticas". Eso indica que la sociología trata con cuestiones normativas, especialmente aquellas relacionadas con la crítica del poder y la dominación, así como aquellas motivadas por la búsqueda de empoderamiento humano y emancipación. También se podría encontrar en posiciones "conservadoras", las cuales expresan cierta nostalgia y deseo por reestablecer las condiciones históricas del pasado. ${ }^{18}$

A pesar de las fortalezas y debilidades de cada una de estas perspectivas, todas ellas nos obligan a tomar seriamente la relación entre la sociología y la filosofía - no sólo histórica e institucionalmente, sino que también analítica y normativamente. Como afirma Chernilo, "las buenas preguntas sociológicas siempre son también, en el fondo, filosóficas" ${ }^{19}$.

En un sentido genealógico, Chernilo recuerda a sus lectores que la idea de una sociología filosófica está inevitablemente relacionada con los intentos previos de desarrollar una antropología filosófica ${ }^{20}$. Esta empresa 
procura combinar conocimiento científico y filosófico sobre la naturaleza de la condición humana, especialmente en términos de su constitución dual:

- en tanto entidades naturales, los humanos son, parcialmente, "controlados por sus impulsos, emociones y su adaptación psicoquímica al mundo"21;

- en tanto entidades culturales, los humanos - debido a sus capacidades constitutivas como especies, como su comportamiento codificado normativamente, su conciencia, autoconocimiento y capacidad de razonar - son "definidos por sus descubrimientos intelectuales, estéticos y, por lo tanto, morales" 22 .

A diferencia de otras criaturas que se encuentran inmersos en el mundo de modo puramente instintivo, los humanos lidian con los misterios de su existencia y del mundo que les rodea. Así, "un humano es un ser que se pregunta qué es un ser humano; los humanos son seres que plantean preguntas antropológicas" 23 . Los humanos están equipados con la capacidad de tomar decisiones racionales, reconocer a sus similares como miembros que comparten un conjunto de propiedades constitutivas de su especie, hacer frente a su inmersión en el mundo natural y cultural, y poner en entredicho potencialmente todo - incluso su propia existencia. ${ }^{24}$ Así, desde el punto de vista de Chernilo, si existen dos sociólogos clásicos que triunfaron al unir los dos géneros intelectuales en los cuales él está interesado (esto es, la sociología y la filosofía), entonces esos dos serían Karl Marx y Max Weber. ${ }^{25}$

La habilidad de diferenciar entre preocupaciones filosóficas/ normativas y empíricas/científicas es esencial al desarrollar una sociología conceptualmente sofisticada, metodológicamente rigurosa, basada en 
evidencias y, en último término, crítica. La interrogante se mantiene, de todos modos, sobre lo que distingue al homo sociologicus ${ }^{26}$ de homines específicos de otras disciplinas sociales - sobre todo, el homo oeconomicus y el homo psychologicus. ${ }^{27}$ El primero se encuentra formado por los roles, normas, condiciones, acciones, fuerzas, estructuras y prácticas sociales. El segundo se encuentra motivado por "el cálculo de posibilidades para la ganancia personal" 28 basado en decisiones racionales. El tercero se compone de patrones conductuales dirigidos por "motivos inconscientes"29 insertos en disposiciones cognitivas. De acuerdo con Chernilo, estas tres ramas científicas dedicadas al análisis sistemático de estos homines, independientemente de sus diferencias, comparten al menos dos características: (1) se encuentran interesadas en la relación entre el individuo y la sociedad, especialmente sobre sus puntos de intersección. (2) En lugar de permitir la formulación de una teoría de la naturaleza humana comprehensiva, cada una de ellas tiende a subrayar la importancia de una característica antropológica específica - esto es, un rasgo constitutivo como especie que es particularmente útil para confirmar la validez de la perspectiva disciplinaria desde la cual se interpreta la interrelación de la agencia individual y las fuerzas sociales.

Una crítica notable que Chernilo articula sobre la "sociología contemporánea mainstream"30 es que "no ha aprendido las lecciones adecuadas" $^{11}$ de la historia, en términos de tomar los asuntos normativos en serio y reconocer que un estudio comprehensivo de la vida social "requiere un principio universalista de humanidad que ofrezca una abarcativa revisión de nuestras características antropológicas definitorias" ${ }^{12}$. En la opinión de Chernilo, incluso el sociólogo francés más influyente de finales del siglo XX, Pierre Bourdieu, "no conceptualizó la normatividad sociológicamente" ${ }^{33}$, a pesar de que tuvo relación con asuntos normativos. Como resultado de ello, de acuerdo con Chernilo, estamos confrontados con una "representación 
"anormativa" de la vida social"34, lo que es equivalente a la "propia distopia de la sociología que acarrea su propio cumplimiento"35. Si, como concluye este autor, fallamos en comprender los fundamentos valorativos de las realidades humanas, entonces no hay lugar para el concepto de "lo normativo" dentro de nuestras - posiblemente reduccionistas - "ontologías de lo social"36.

Más aun, el surgimiento del posthumanismo ha hecho que los debates sobre la naturaleza de la humanidad sean aun más complejos. ${ }^{37}$ Sobre este asunto es clave el debate en el que hemos entrado en un "mundo posthumano". Las controversias acerca del rol de la inteligencia artificial, la ciencia cognitiva, biotecnología y la tecnología digital, así como las disputas sobre el cambio climático y el estado de la vida de otras criaturas en nuestro medio ambiente, indican la emergencia de un mundo donde los límites tradicionales - como aquellos entre "lo no-humano" con "lo humano", "lo natural" y "lo cultural", "lo objetivo" y "lo normativo" - aparecen cada vez más borrosos. La pregunta sobre "lo que nos hace humanos"38 permanece como una fuente de acaloradas discusiones. ${ }^{39} \mathrm{El}$ trabajo de los académicos que han sido acertada o equivocadamente asociados con la etiqueta del "posthumanismo" tienen a "rechazar el fundacionalismo que subyace detrás de las tradicionales ideas "humanistas"" 40 sobre el mundo en general y sobre la sociedad en particular. Al explorar principios clave de esta postura antifundacionalista, Chernilo revisa tres versiones del pensamiento posthumanista -a saber, las contribuciones realizadas por Bruno Latour ${ }^{41}$, Rosi Braidotti ${ }^{42}$ y Andy Clark ${ }^{43}$.

- Latour ha desarrollado la teoría del actor-red que trasciende la tradicional dicotomía entre "lo humano" y "lo no-humano". Una parte importante de esta empresa es el intento de ubicar la agencia en redes, las cuales, por definición, están compuestas por elementos humanos y no- 
humanos. Las redes, en el sentido de Latour, se pueden describir como "series de asociación(es)", "series de instauración(es)" y "cadenas de referencia(s)". ${ }^{44}$ Paradójicamente, su estabilidad, solidez y universalidad no se pueden divorciar de su maleabilidad, flexibilidad y particularidad. ${ }^{45}$ En un mundo constituido por "un eterno flujo de redes"46, las tradicionales categorías ontológicas dualistas (como "naturaleza"/"cultura" e "individuo"/"sociedad") necesitan ser comprendidas como híbridos, y no como dominios de existencia independientes o completamente aislados.

- Con base en los escritos de Gilles Deleuze y Félix Guattari, Braidotti presenta una crítica radical al humanismo. En un estilo post-Heideggeriano, ella concibe el "Humanismo" como una "macro-ideología violenta y excluyente del Occidente"47, la cual encarna las dimensiones negativas y perjudiciales, si no malvadas, del proyecto de la modernidad. ${ }^{48}$ En su opinión, como Chernilo detalla, el humanismo no sirve como una "articulación viable de nuestra sensibilidad normativa contemporánea" , pues "ya está muerto" 50 . La visión de esta autora en su crítica severa al antropocentrismo, androginismo y racismo (y otras formas de discriminación) $)^{51}$, no tiene dificultad en "apelar de manera ubicua a los mismos valores humanistas tradicionales"52 a los que ella pretende deconstruir en su ataque al humanismo. Paradójicamente, entonces, su enfoque es, al mismo tiempo, promoderno y antimoderno: promoderno, en el sentido de que su proyecto está impulsado por "la necesidad de hablar "en nombre de" y, de ese modo, orientándose hacia "un problema político esencialmente moderno"54; antimoderno, en el sentido de que ella desconfía de "los valores y las instituciones del mundo moderno"55, dada su complicidad con - si no declarada aprobación y creación proactiva de - los mecanismos de dominación social. Una fuerte limitación de este tipo de posthumanismo es que estos "no pueden articular consistentemente sus posiciones normativas, 
pues no pueden clarificar (...) cuál realmente es el núcleo humano a partir del cual están preparados para actuar positivamente" ${ }^{16}$. En breve, son culpables de estar encerrados en una "contradicción performativa"57, en el sentido de que, efectivamente, suscriben a un "antinormativismo normativista" y un "normativismo antinormativista" (y, correspondientemente, un "humanismo antihumanista" y un "humanismo antihumanista"), dependiendo del lado del argumento que enfaticen en un contexto particular. No se puede tener los pies en ambos lados.

- Clark, quien es uno de los propulsores de la tesis de la "mente extendida" 58 . Insiste en que el rol central que tienen los factores externos incluyendo los aparatos tecnológicos - juegan un papel importante durante el desarrollo de los procesos cognitivos. Este enfoque puede ser considerado como una versión externalista del posthumanismo, el cual "apunta hacia el relajamiento - si no directamente hacia la disolución - de la idea del ser humano y sus poderes agenciales autocontenidos"59. Según esta visión, nuestro entorno es un elemento integral - si no un fundamento ontológico - de nuestro aparato mental. En este marco, Chernilo pone atención a tres presupuestos que subyacen en esta perspectiva:

I. Los actores humanos se definen "por el constante juego mutuo entre mente, cuerpo y mundo"60.

II. El diseño de robots humanos, principalmente en términos de su inteligencia y movilidad, brinda señales sobre las características que nos hacen humanos y sobre los hechos de que "el agente humano (...) es un experto natural para convertirse en un experto"61, como Clark señala elocuentemente.

III. En la era actual, los humanos han evolucionado hacia "cyborgs nacidos-naturalmente"62. Debido a la constante innovación tecnológica, 
los desarrollos evolutivos están cada vez más moldeados por la interpenetración e hibridación de plantas, animales y humanos.

Para Chernilo, estos tres supuestos son parte de su agenda posthumanista, en la cual parecería que la especie humana se han embarcado en una vía que no sólo muestra que lo natural puede enseñar a lo artificial, sino también que "lo artificial puede enseñar a lo natural"63. Independientemente de si nos enfocamos en plantas, animales, humanos, robots o ciborgs, el posthumanismo refleja el fin del sueño moderno de la "supremacía y la excepcionalidad humana"64. En este contexto, es imperativo reconocer que "la cognición individual (...) se centra en nuestro organismo incluso cuando no está limitada al organismo"65. Así, la expansión cognitiva es inconcebible sin, pero no necesariamente determinada por, un núcleo orgánico. ${ }^{66}$

Lo que sigue en los capítulos subsecuentes es un tour de force. En el Capítulo 1, Chernilo contextualiza los debates modernos sobre el humanismo. Lo hace al elucidar las contribuciones hechas por Jean-Paul Sartre, Martin Heidegger y Jacques Derrida acerca de nuestra comprensión de los "valores humanistas" y la "interrogante antropológica". En los capítulos restantes, explora lo que refiere como las siete propiedades antropológicas centrales basándose en el pensamiento de siete prominentes pensadores: la autotrascendencia (Arendt), la adaptación (Parsons), la responsabilidad (Jonas), el lenguaje (Habermas), las evaluaciones fuertes (Taylor), la reflexividad (Archer) y la reproducción de la vida (Boltanski). Cada capítulo ofrece un profundo análisis de cada una de las propiedades previamente mencionadas desde la perspectiva de su respectivo académico. Finalmente, el "Epílogo"67 sintetiza un sucinto y crítico resumen de los principales temas examinados en el libro. Dada la relevancia del argumento general de Chernilo, es valioso considerar estos tópicos a detalle. 
La idea de una antropología filosófica - como lo propusieron pensadores como Max Scheler ${ }^{68}$, Ernst Cassirer ${ }^{69}$ y Helmuth Plessner ${ }^{70}$ - se enfrenta a un dilema: por una parte, puede ser rechazada como "ciencia pobre" al ser "muy filosófica"; por otra parte, puede ser descartada como "filosofía pobre" al ser "muy empírica"71. Una línea similar de críticas puede ser dirigida al proyecto de sociología filosófica - y a la teoría social, de manera más amplia. La filosofía, en particular, tiene la reputación de ser una disciplina que ha sido protegida sistemáticamente por guardianes académicos, que se resisten a admitir a académicos de dominios de investigación adyacentes - notablemente científicos sociales - incluyendo a la antropología y la sociología.

En relación con su propio plan, Chernilo sostiene que "su propósito nunca fue ofrecer un conjunto completo o exhaustivo de características antropológicas con las cuales se puede definir lo humano de los seres humanos"72. Por el contrario, su objetivo es iluminar "aquellas características antropológicas que son de vital importancia en dos niveles"73: en el primer nivel, estas características son "autónomas con respecto a la sociedad, incluso si su propia actualización es social en sí misma"74; en el segundo nivel, aquellas que permiten "articular de manera más explícita el terreno sobre el cual las demandas normativas se hacen en la sociedad"75, dejando de lado si se realizan desde expertos o actores ordinarios. Una vez examinadas las siete propiedades antropológicas, las cuales en su opinión cumplen estos requerimientos, Chernilo intenta demostrar que una cuidadosa atención nos permite "rearticular una idea universalista de humanidad como algo que los humanos hemos creado por nuestra cuenta"76. Él resume la idea principal de su proyecto de esta manera: 
Sólo una idea de la humanidad que proviene de las características propias de los humanos, que permite a los humanos reflexionar sobre sí mismos como creadores de sus propias ideas e instituciones, puede, entonces, volverse una idea normativa: un ser humano es un ser que hace antropología filosófica. ${ }^{77}$

Sobre esta visión, Chernilo, en su "Epílogo"78, analiza algunos temas que se encuentran dentro de su argumento.

Un punto inicial es la idea de "descripciones normativas". ${ }^{79}$ Como lo ilustra Chernilo a lo largo del libro, "la tensión entre proposiciones descriptivas y enunciados normativos ha sido central en el desarrollo de las ciencias sociales de los últimos 150 años" ${ }^{80}$. Los científicos sociales están frente de una tarea doble: (1) ofrecer representaciones precisas y confiables del mundo; y (2) realizar juicio de valor sobre la calidad y deseabilidad de prácticas y órdenes sociales. En otras palabras, los científicos sociales hacen frente a la pregunta de diagnóstico sobre cómo es el mundo social y las preguntas normativas sobre cómo debería estar organizado. La insistencia de Chernilo en el concepto de "descripciones normativas" añade otro nivel de complejidad a este tema. Basándose en el trabajo de Hannah Arendt ${ }^{81}$, y enfatizando la validez de su afirmación de que, los campos de concentración son, literalmente, "el infierno en la tierra""82, Chernilo señala que la descripción de ciertos fenómenos sociales (que existen objetivamente) dependen de nuestra capacidad cognitiva (efectivamente evaluativa) para dar cuenta de sus dimensiones normativas. Esta perspectiva está ligada inevitablemente con tres compromisos: 
I. una concepción universalista de humanidad sobre la cual todos los individuos son tratados como miembros de la misma especie, unidos por un conjunto de capacidades antropológicas - dejando de lado el grado con el cual están divididos por variables sociológicas como clase, etnicidad, género, edad y habilidades;

II. una concepción evaluativa de la normatividad, de acuerdo con cual se determina cualitativamente las formas de socialización ideológicas, institucionales y del comportamiento, en términos del grado en el que pueden promover u obstruir "el desarrollo de nuestros potenciales humanos genéricos"83;

III. una concepción crítica de las ciencias sociales, de acuerdo con las cuales "el registro explicativo (...) se vuelve a conectar con las preguntas normativas" 84 que usualmente están planteadas en conjunto con modos de indagación filosófica.

Otro tema que se encuentra a lo largo del análisis de Chernilo es aquel que se describe como "el escándalo de la necesidad humana por una antropología"85. Este tema se refiere a lo que Chernilo considera un dilema importante en la antropología de Immanuel Kant, a saber, el escándalo de la razón (como se discute en los Capítulos 2, 3 y 4). ${ }^{86}$ De acuerdo con Chernilo, este dilema consiste en la siguiente tensión entre estos presupuestos:

Por un lado, la razón es, por decirlo de algún modo, trans-antropológica, en el sentido de que "la integridad lógica de las categorías de entendimiento"87, incluyendo el imperativo categórico de la ética deontológica de Kant, reside en un "llamado a la universalidad" 88 que, debido a su búsqueda de pureza racional, "no es específicamente humana"89.

Por otro lado, la razón es intra-antropológica, en el sentido de que la constitución socio-histórica de nuestras categorías de entendimiento, 
incluyendo las contingencias espaciotemporales que permean las construcciones contextualizadas y las aplicaciones de la moralidad, intermedian en la presencia de particularidades que, "adaptadas a las necesidades humanas antropocéntricamente"90, no se pueden divorciar de los recursos cognitivos y performativos, debido a las cuales se construyen sociedades estructuralmente distintas.

Así, reflexionando sobre el escándalo de la razón, nos enfrentamos a otro problema: parecería que, precisamente en relación con las cuestiones existenciales más importantes, nosotros, como miembros de una misma especie, hemos encontrado que es muy difícil, incluso quizá imposible, proveer respuestas satisfactorias a "las grandes preguntas" que surgen por virtud de la razón. Así, tanto las preguntas trascendentales - sobre, por ejemplo, el significado de la vida y la muerte, la (no)existencia de Dios, la (im)posibilidad de una vida después de la muerte - como las preguntas inmanentes - como, por ejemplo, aquellas sobre cómo se debe (y no se debe) vivir la vida de cada uno - continúan siendo preocupaciones que, a pesar del poder epistémico de la racionalidad humana, no van a poder ser resueltas de manera categórica e irrefutable. En este sentido, el argumento de Chernilo respecto a este desafío es triple:

I. Como especies en busca de conocimiento, jamás hemos estado y jamás estaremos satisfechos con las respuestas (esencialmente tentativas) que buscamos a las preguntas existenciales, incluyendo las preguntas sobre lo que nos hace humanos.

II. La búsqueda de respuestas a estas preguntas no sólo es un problema cognitivo sino también uno normativo.

III. Lo que se podría llamar "antropocentrismo cotidiano" está construido en nuestra condición como especie en tanto "los seres 
humanos somos un tema central y la causa de la preocupación únicamente para nosotros mismos como humanos"91.

Otro aspecto sobresaliente del libro de Chernilo es "la relación entre la ciencia y la filosofía"92. Al defender el proyecto de una "filosofía sociológica" (notablemente en los Capítulos 3, 4, 5 y 8), este autor insiste en que "las preocupaciones filosóficas no son independientes de las científicas" 93. Como lo ilustra el surgimiento del posthumanismo, difícilmente algún punto de vista filosófico (en áreas de investigación como la ontología, la epistemología, ética, lógica y estética) puede ser defendido, a menos que esté basado en hallazgos importantes de las ciencias sociales y naturales.

Con esto no se pretende sugerir que, en adelante, las indagaciones filosóficas no sean relevantes para la vida humana en general y la investigación científica en particular. Por el contrario, esto significa reconocer que, dentro de los numerosos ámbitos de producción y circulación del conocimiento, el balance de poder ha cambiado. En vez de concebir la relación entre la filosofía y la ciencia en términos de una antinomia epistémica, es vital comprender su interdependencia. Lejos de buscar "las condiciones para su propia disolución"94, la filosofía necesita admitir que se encuentra en una posición complicada que requiere "explicar filosóficamente cómo se ha generado la debacle de sus propias pretensiones de conocimiento"95. Inposiblemente, las "grandes preguntas", incluyendo la variabilidad espaciotemporal de los contextos en los cuales se han producido estas interrogantes, siempre serán temas cuyo estudio comprehensivo requieren una combinación de investigación científica y filosófica.

La búsqueda de conocimiento sobre nuestro estado en el universo puede ser considerada como una "constante transcultural y transhistórica"96, en el sentido de que forma parte integral de la condición humana. Una parte 
de este recorrido es la construcción de "autoconocimiento" y procesos de "auto-objetivización"97, donde los humanos pueden definir su lugar en el universo, mientras movilizan sus recursos cognitivos para estabilizar su "adaptación orgánica"98, lo cual les permite acomodarse a sus entornos sociales y naturales. Así, "el auto conocimiento como una proposición cognitiva no necesariamente lleva a la autolegislación como una demanda normativa"99; dicho de otro modo, la razón (Verstand) no es una garantía de prudencia (Vernunft), si se deja de lado la capacidad de juzgar (Urteilskraft).

Otro tema central discutido por Chernilo se trata de "la continuidad de la naturaleza humana en las ciencias sociales" ${ }^{100}$. La pregunta por la "naturaleza humana" no se eliminará; se planteará continuamente y se debatirá por científicos sociales - incluso (o, quizás, especialmente) por los constructivistas, que rechazan esta idea y cualquiera asociada a ella, con el argumento de que ello lleva al esencialismo y/o determinismo biológico. Por su parte, como lo ilustra Chernilo en los Capítulos 3, 5 y 7, él está de acuerdo con la afirmación de que "las ideas de lo social necesitan ser evaluadas en su propio campo y en sus propios términos" ${ }^{101}$. Contrario al individualismo metodológico, los fenómenos sociales no pueden ser explicados por las preferencias personales, motivos subjetivos y/o sus decisiones racionales. Por ejemplo, la sociabilidad no es un fenómeno exclusivamente humano. Otras especies - como "las hormigas, abejas delfines y chimpancés"102_ también son profundamente sociales.

Esta pregunta, entonces, tiene relación con la medida en que la sociabilidad humana difiere en relación con otras especies. Algunos elementos humanos que son constitutivos de la humanidad - como la cultura, el lenguaje, la conciencia, el autoconocimiento, la moralidad, los juicios estéticos y la razón - necesitan ser tomados en cuenta cuando se analicen estos temas. Si son correctos los supuestos de Chernilo de que "otras especies 
no viven en el escándalo de la razón"103 (o, a su vez, en los escándalos de la cultura, el lenguaje, la conciencia, el autoconocimiento, la moralidad o el juicio estético), entonces es probable que nuestras capacidades cognitivas, las cuales se desarrollan a través de la interacción y comunicación con otros compañeros (Mitmenschen), representen una parte esencial de lo que nos hace "humanos". Dentro de este espíritu - ampliamente antropológico - Chernilo busca "ofrecer una revisión explícita de aquellas propiedades humanas que permiten que los humanos reflexionen acerca de su propia especificidad y valía"104 y, por lo tanto, en las características que, a pesar de que no surgen "sobre" la naturaleza, hace que los humanos sean en algunas características fundamentalmente diferentes a otras criaturas.

Finalmente se encuentra "el problema del antropocentrismo"105. Basándose en el trabajo de Edmund Husser1 ${ }^{106}$, Chernilo afirma que la "ciencia y la filosofía no están particularmente interesadas en el ser humano" ${ }^{107}$. En términos de su perspectiva de investigación, la primera se enfoca en "la naturaleza de la vida orgánica y la estructura del cosmos"108, mientras que la última se concentra en "la razón y la intencionalidad"109. Con el fin de superar el antropocentrismo es necesario realizar un "acto dual de descentramiento"110.

I. Los humanos deben superar su proclividad a ponerse a sí mismo "en el centro de las explicaciones sobre el funcionamiento del cosmos, la cultura y la sociedad"111.

II. Los humanos necesitan estar preparados para "aceptar que no hay nada necesario sobre su propia existencia"112.

El "giro copernicano"113 no sólo muestra que el centro de nuestro sistema solar es el sol, y no la tierra, sino también que, desde un punto de vista científico, es aconsejable ser cautelosos de las preocupaciones 
filosóficas y teológicas que surgen de la relativización de la posición de los seres humanos en el universo. Si la deconstrucción del antropocentrismo supone asegurar que los humanos dejen de "ponerse a sí mismos como el estándar sobre el cual se debe medir todo lo que sucede en el mundo"114 (y más allá), entonces un punto de vista descentrado debería ser ilustrativo, en el sentido de que permita que las especies dominantes del planeta tierra pongan en perspectiva su existencia y su ambición, auto percibida como moralmente superior, para dominar una pequeña parte del universo como su hegemonía planetaria.

Ciertamente, "el hecho de que los seres humanos no son el centro del universo no cambia el hecho de que ellos son el centro de su propia vida humana"115. Después de todo, aprendemos a relacionarnos con el mundo externo y nuestro mundo interno al interactuar con otros seres humanos. La razón (Verstand) no se puede desarrollar sin la habilidad individual de poder ser parte de procesos de comunicación (Verständigung). La conexión semántica entre la razón (Verstand) y la comunicación (Verständigung) no es una coincidencia: señala la interrelación evolucionaria de capacidad (cognitiva) para razonar y la capacidad (relacionada al reconocimiento) para relacionarnos con el mundo a través de nuestra interacción mutua ${ }^{116}$. Así, "nuestro crecimiento de Mund a Mündigkeit ha sido boca a boca"117. De acuerdo con nuestro espíritu intersubjetivo, Debating Humanity no es un intento de desenraizarnos del núcleo social de la existencia humana. Por el contrario, intenta llamar la atención al hecho de que nuestra sociabilidad permea todas nuestras características de humanidad constitutivas como especie.

En lo que sigue del artículo, evaluaremos algunas limitaciones y aspectos controvertibles del libro de Chernilo. 


\section{Reflexiones críticas}

\section{¿Falacias ad logicam?}

Una notable debilidad del análisis de Chernilo consiste en que, en algunas ocasiones, crea "argumentos ad logicam" para defender su versión de "sociología filosófica". Para esto, sólo se considerará un ejemplo: si bien "las ideas de la supremacía y el excepcionalismo humano"118 son una parte constitutiva de los imaginarios antropocéntricos modernos, es difícil imaginarse a algún científico social que seriamente argumente que "los humanos son seres autocontenidos"119. Siguiendo este ejemplo, se pueden encontrar numerosas falacias del "ad logicam" en el libro de Chernilo. Hay que reconocer que cumplen la vital tarea de ilustrar la esencia de una posición al contrastar con una construcción relativamente arbitraria de puntos de vista radicalmente opuestos. De todos modos, estas afirmaciones continúan siendo una falacia, pues están basadas en proposiciones erróneas utilizadas para que un argumento aparezca más fuerte, y quizás también más original, que el que alega el oponente. Por supuesto, muchos académicos e investigadores son, en un mayor o menor grado, culpables de esta "práctica" cuando desarrollan y defienden sus argumentos. Aun así, esta aceptación autocrítica no provee una validez epistémica a las falacias "ad logicam".

¿Una limitación metodológica como una limitación sustantiva?

Una limitación importante del libro de Chernilo es que cada capítulo se concentra en un máximo de dos textos, los cuales - desde del punto 
de vista del autor - son útiles en términos de ilustrar la concepción de lo humano de pensadores específicos. ${ }^{120}$ Esta aproximación metodológica es problemática por algunas razones:

I. No está del todo claro cuáles son los criterios que Chernilo aplicó al escoger una obra en particular. La decisión de optar por un máximo de dos textos de los cuales "yo considero que logran visibilizar su concepción de lo humano"121 es una decisión metodológica bastante arbitraria, pues otros estudiosos de las obras de cada autor podrían sugerir que ellos opinan que podrían lograr resultados más convincentes al referirse a otros textos escritos por los mismos autores elegidos por Chernilo.

II. Centrarse sólo en un máximo de dos textos por autor parecería que no es suficiente, en la medida en que estos representan una estrecha muestra de sus obras, especialmente a la luz del hecho de que los académicos en cuestión han producido numerosas obras importantes. Si se reduce la muestra a uno (o dos) texto(s) por cada uno de ellos, se corre el riesgo de brindar una revisión simplista y limitada de lo que, en realidad, puede ser una imagen que es mucho más compleja y, en muchos casos, llena de tensiones.

III. Muchos grandes pensadores pasan a través de diferentes fases intelectuales - a saber, una fase "temprana", "intermedia" y "final". Muchos de ellos reconsideran sus principales opiniones sobre aspectos clave, a veces de manera radical. Es difícil que una cuestión tan fundamental como su entendimiento de lo humano sea completamente consistente (implícita o explícitamente). Con el fin de proveer una imagen precisa de su concepción de lo humano, la cual puede variar a lo largo de las distintas etapas de sus carreras, parecería que es necesario abordar al menos un trabajo seminal de cada fase, subrayando las tensiones dentro de su trayectoria intelectual - en los casos que fuera necesario - respecto a ciertos temas de particular importancia. 
¿La humanidad de quiénes?

El análisis de Chernilo se centra en el análisis de siente pensadores (o diez, si incluimos el Capítulo 1): Arendt, Parsons, Jonas, Habermas, Taylor, Archer y Boltanski (así como Sartre, Heidegger y Derrida). En términos de la "demografía" que subyace a este estudio, los autores podrían ser clasificados de la siguiente manera ${ }^{122}$ :

- Género:

- De sexo femenino (Archer, Arendt)

- De sexo masculino (Boltanski, Derrida, Habermas, Heidegger, Jonas, Parsons, Sartre, Taylor)

$\rightarrow$ La abrumadora mayoría de los principales académicos que caracterizan a este volumen son hombres.

- "Raza"/etnicidad:

- Blancos (Archer, Arendt, Boltanski, Derrida, Habermas, Heidegger, Jonas, Parsons, Sartre, Taylor)

$\rightarrow$ Todos los académicos que caracterizan a este volumen son blancos.

- Religión/etnicidad:

- Católicos (Archer, Boltanski, Heidegger, Sartre, Taylor)

- Judios/judíos seculares (Arendt, Boltanski, Derrida, Jonas)

- Protestantes/congregacionalistas (Habermas, Parsons)

$\rightarrow$ En términos de su contexto etnocultural, la mayor cantidad de académicos presentes en este volumen son Judeocristianos. 
- Origen geográfico:

- Anglo-europeos (Archer)

- Europeo-continentales (Arendt, Boltanski, Derrida, Habermas, Heidegger, Jonas, Sartre)

- Norteamericanos (Parsons, Taylor)

$\rightarrow$ La gran mayoría de los principales académicos de este volumen son de Europa continental, dos son norteamericanos, y una es anglo-europea. No hay figuras intelectuales de otros continentes que jueguen un rol central en el análisis de Chernilo.

- Origen nacional:

- Británica (Archer)

- Canadiense (Taylor)

- Francés (Boltanski, Derrida, Sartre)

- Alemán (Habermas, Heidegger)

- Alemán-americano (Arendt, Jonas)

- Estadounidense (Parsons)

$\rightarrow$ La mayor cantidad de académicos que caracterizan a este volumen son alemanes/alemanes-americanos, con franceses en segundo lugar, y británicos, canadienses y estadounidenses conjuntamente en el tercer lugar. No hay representantes de nacionalidades no-europeas o no-angloamericanas.

- Especificidad lingüística:

- Angloparlantes (Arendt, Parsons, Jonas, Taylor, Archer)

- Francófonos (Boltanski, Derrida, Sartre)

- Germanoparlantes (Arendt, Habermas, Heidegger, Jonas)

$\rightarrow$ Una importante mayoría de los principales pensadores que se analizan en este volumen son angloparlantes y/o germanoparlante y/o francófonos. Así, en términos de su especificidad lingüística, sus grandes escritos (esto 
es, el idioma principal con el que han trabajado), sus obras están firmemente situadas en el horizonte hermenéutico de los tres lenguajes europeos más influyentes en las humanidades y ciencias sociales.

- Situación histórica:

- Académicos cuyos trabajos se produjeron en el periodo de la modernidad temprana/moderna (a inicios y a mediados del siglo XX) - a saber: Heidegger (1889-1976), Parsons (1902-1979), Jonas (1903-1993), Sartre (1905-1980), Arendt (1906-1975)

- Académicos cuyos trabajos se produjeron en el periodo de la modernidad tardía o periodo contemporáneo (a mediados/finales del siglo XX, y a inicios de siglo XXI) - a saber: Habermas (1929-), Derrida (19302004), Taylor (1931-), Boltanski (1940-), Archer (1943-)

$\rightarrow$ De manera general, los principales académicos que caracterizan a este volumen son pensadores modernos o de la modernidad tardía - esto es, produjeron sus obras clave a inicios/mediados del siglo XX, a mediados/ finales del siglo XX, o a inicios del siglo XXI.

- Pertenencia generacional:

- Nacidos en la última década del siglo XIX (1890-1899) - a saber, Heidegger (1889-1976)

- Nacidos en la primera década del siglo XXI (1900-1910) - a saber, Parsons (1902-1979), Jonas (1903-1993), Sartre (1905-1980), Arendt (1906-1975)

- Nacidos a mediados del siglo XX - a saber, Habermas (1929-), Derrida (1930-2004), Taylor (1931-), Boltanski (1940-), Archer (1943-)

$\rightarrow$ De manera general, los principales académicos de este volumen (con una excepción) nacieron a inicios o a mediados del siglo XXI. La influencia de sus respectivos trabajos estuvo relacionada, en un mayor o menor grado, por el 
clima político de los periodos de posguerra (i.e. después de la Primera Guerra Mundial y la Segunda Guerra Mundial, respectivamente).

- Posicionamiento discursivo/ideológico:

- Reaccionario-conservador (Heidegger)

- Moderado-conservador (Jonas, Parsons)

- Moderado-progresista (Archer, Derrida, Habermas en sus últimas etapas, Taylor)

- Radical-progresista (Arendt, Boltanski, Habermas en sus primeras etapas, Sartre)

$\rightarrow$ Una importante mayoría de los principales académicos de este volumen, de manera general, son progresistas en términos de su posicionamiento normativo.

- Contexto disciplinario y/o especialidad(es) académica(s):

- Filosofía (Arendt, Derrida, Heidegger, Jonas, Sartre, Taylor)

- Sociología (Archer, Boltanski, Parsons)

- Filosofía y sociología (Habermas)

$\rightarrow$ Seis de los diez pensadores de este volumen son conocidos principalmente como filósofos, tres de ellos como sociólogos, y uno de ellos es filósofo y sociólogo.

No tiene mucho sentido tomar esta perspectiva "demográfica" del estudio de Chernilo muy lejos. No obstante, ilustra las críticas que se pueden formular, en el sentido de que su investigación sufre de los típicos "-ismos" que - de acuerdo a los científicos sociales interesados en las relaciones de poder interseccionales - necesitan ser cuestionadas, deconstruidas y superadas: sexismo canónico ("machismo"); racismo canónico ("todos 
blancos"); etnocentrismo canónico (predominantemente judeo-cristiano); canónicamente Occidental (exclusivamente Europeo y Angloamericano); nacionalismo canónico (predominantemente nacionalidades europeas y norteamericanos); linguocentrismo canónico (Anglocentrismo, Germanocentrismo y/o Francocentrismo); modernismo canónico ("todos modernos"); edadismo canónico (únicamente generaciones "antiguas"); ideologismo canónico (todos posicionados en el espectro político de la izquierda-derecha); tribalismo canónico (todos sociólogos o filósofos).

Así, sus detractores - incluyendo postmodernistas, postestructuralistas, postcolonialistas, feministas e interseccionalistas - objetarán que la selección de pensadores de Chernilo está sesgada hacia hombres, blancos, judeocristianos, occidentales, del Norte, anglo-/germano-/francófonos, modernos, "viejos", políticamente predecibles y limitados académicamente a ciertos límites disciplinarios. En suma, Chernilo puede ser acusado de permanecer atrapado en los cánones establecidos de las ciencias sociales y humanidades. Como consecuencia, sobre este punto surge una comprensión de la humanidad que, a pesar de que pretende ser "universalista" nominalmente, es particularista, en la práctica. Dejando de lado si se está de acuerdo o en desacuerdo con esta línea argumentativa - cada vez más común -, habría sido útil que Chernilo desarrollase explícitamente esta fuente de controversia con cierto detalle.

\section{¿Entre normativismo contextualista y normativismo fundacionalista?}

Todo el proyecto de Chernilo se fundamenta en el supuesto de que "las características antropológicas que compartimos como miembros de la especie humana continúan siendo la mejor opción para justificar argumentos 
normativos"123. Sin importar cuán prometedora pueda ser esta orientación universalista - y, por ende, cosmopolita -, parecería que deberíamos aceptar que esta premisa tiene relación sobre todo con argumentos fundacionales, y no contextuales. Para ser precisos, la cita previa podría ser reformulada de esta manera: "las características antropológicas que compartimos como miembros de la especie humana continúan siendo la mejor opción para justificar argumentos normativos fundacionales". Entonces, la validez de la afirmación previa de Chernilo, la cual es crucial para su proyecto universalista, depende del tipo de afirmación que busca defender. Es decir, ciertamente es válida para argumentos fundacionalistas, pero no necesariamente para argumentos no-fundacionalistas (contextuales, por ejemplo).

De acuerdo con lo que se infiere a partir de la afirmación de Chernilo, ¿es cierto que nuestras características antropológicas son la mejor opción para justificar argumentos normativos? Por ejemplo, ¿quién debe realizar el lavado de ropa, o debe existir otro referéndum sobre la membresía del Reino Unido a la Unión Europea? O bien, ¿sobre cuánta leche en polvo - o leche condensada - debe contener una leche chocolatada? Es cierto que algunos argumentos normativos importantes (incluyendo aquellos realizados en el área de la política social) están relacionados intrínsecamente con nuestras características antropológicas - como temas sobre la distribución asimétrica de poder y recursos que se producen por la influencia de cruciales variables sociológicas como la clase, etnicidad, género, edad y habilidad. Incluso en el ámbito de la inequidad social las características antropológicas que compartimos - a pesar de que puedan servir como un punto de referencia general para justificar posiciones normativas - no determinan, en último término, el modo cómo se desarrollen estos argumentos que, en el mejor de los escenarios, lo harán mediante la coacción sin fuerza del mejor 
$\operatorname{argumento}^{124} \mathrm{o}$, en el peor de los escenarios, mediante la fuerza del mayor poder legítimo $^{125}$.

\section{¿Falsas dicotomías?}

Una notable característica de la tesis de Chernilo es que se fundamenta en una serie de dicotomías, algunos de los cuales sus críticos pueden encontrar problemáticas (en el mejor de los casos) o insostenibles (en el peor de los casos). Se señalará algunas de ellas:

Natural vs. consciente:

(...) un enfoque dual de los seres humanos surge y debe ser preservado, debido a la dualidad de la condición humana en sí misma: por un lado, los humanos son parcialmente cuerpos naturales que están controlados por sus impulsos, emociones y su adaptación fisicoquímica al mundo; y, por otro lado, son seres parcialmente conscientes de que se encuentran definidos por sus hallazgos intelectuales, estéticos y morales. ${ }^{126}$

La dicotomía entre "lo natural" y "lo consciente" está lejos de no ser problemática. Los humanos no son la única especie equipada de un aparato cognitivo complejo. ${ }^{127}$ Ciertamente, la capacidad para desarrollar habilidades intelectuales puede ser un privilegio distintivo como especie de los seres humanos. No obstante, hay importantes evidencias que sugieren que otras especies también tienen el sentido de la apreciación estética de mundo, así como un sentido del juicio moral. ${ }^{128}$ A menos que relacionemos estas propiedades a la racionalidad (en el sentido triple de la razón (Verstand), la prudencia (Vernunft) y la capacidad de juzgar (Urteilskraft)), no es del 
todo obvio en qué medida las propiedades antropológicas previamente mencionadas son exclusivamente humanas. En caso de que no, entonces la dicotomía "natural/consciente" de Chernilo colapsa.

Biológico vs. social: Chernilo acierta al afirmar que "la proposición de que los humanos son seres sociales sólo es otra manera de decir lo obvio" ${ }^{129}$. Lo mismo aplica para la afirmación de que los humanos son seres biológicos. Así, "los enfoques como la sociobiología son insuficientes"130 pues fallan al señalar "los aspectos existenciales en las interrogantes acerca de lo que es un ser humano"131. Este hallazgo, en todo caso, no supera la dicotomía entre "lo biológico" y "lo social" - especialmente en términos de la división entre "lo natural" y "lo adquirido"-, la cual todavía es central en los debates sobre la relación entre la genética y los factores ambientales que permean la condición humana. Asimismo, no está claro cuáles son "los aspectos existenciales" 132 que definen lo que nos hace efectivamente humanos - por no mencionar el hecho de que, posiblemente, estos tienen componentes biológicos y sociológicos. Por un lado, se podría enfocar en la cultura, el lenguaje, la consciencia, el autoconocimiento, la moralidad, el juicio estético, la razón, o cualquier otro aspecto de la humanidad. Todas nuestras características constitutivas como especie se han desarrollado, y continúan desarrollándose, a partir de una compleja interacción entre factores genéticos y ambientales. Esta interacción subyace en el corazón de la evolución humana. Dada la íntima interrelación de factores genéticos y ambientales, se podría poner en cuestión la validez y la utilidad de la distinción entre "lo biológico" y "lo social". 
Natural vs. cultural:

El cuerpo humano tiene una posición ambivalente para los mismos seres humanos: es un objeto del mundo natural, es el "contenedor" de nuestras características antropológicas y también es un artefacto cultural. ${ }^{133}$

A primera vista, esta afirmación describe, de manera sucinta y precisa, la ambivalencia de la condición humana, enfatizando nuestra inmersión en el mundo natural y en el mundo cultural, los cuales han dejado su huella en la genealogía del cuerpo humano, el vehículo de nuestras capacidades constitutivas como especie. Con un análisis más cercano la afirmación previa resulta problemática en algunos aspectos:

I. Esto es válido no sólo para los humanos sino también para los nohumanos, pues otras especies - incluyendo a los primates no-humanos también desarrollan patrones de comportamiento culturalmente variables y específicos a un contexto. ${ }^{134}$

II. Brinda una visión dualista de nuestra existencia en el mundo - en vez de una visión multinivel. En cuanto tal, no captura nuestra situacionalidad espaciotemporal en ámbitos de existencia físicamente constituidos y socialmente codificados. Además, no resalta el grado a través del cual un actor experimenta el mundo objetivo y su mundo normativo, por medio de su mundo subjetivo, para el cual tiene un acceso privilegiado.

III. Falla al ilustrar el grado en el que la diferenciación conceptual entre "lo natural" y "lo cultural" se encuentra fundamentada en la construcción epistémica - y, a su vez, interpretativa - de tipos ideales. ${ }^{135}$ Estos tipos ideales pueden distorsionar la interrelación ontológica de "lo natural" y "lo cultural" en las formas de vida humana. 
Es poco sorprendente, entonces, que Chernilo realice la afirmación antropocéntrica de que "el rasgo humano más importante es el hecho de que venimos a un mundo que, por el hecho de que nos preexiste, se nos presenta como un reto" ${ }^{136}$. Nuevamente, se debe admitir que otros seres vivientes también experimentan el mundo como un desafío y que también los preexiste. Se podría argumentar (en un estilo antropocéntrico) que - debido a nuestra constitución psicológica y por motivo de las múltiples maneras en las que nos acoplamos, atribuimos sentido y actuamos sobre el mundo - nuestra existencia es un mayor desafío. Si añadimos a la ecuación ciertos elementos constitutivos como especie - como la cultura, el lenguaje, la conciencia, el autoconocimiento, la moralidad, el juicio estético y la razón (en conjunto con el trío de la razón (Verstand), la prudencia (Vernunft) y la capacidad de juzgar (Urteilskraft)) -, entonces este desafío se vuelve más complicado todavía. De este modo, sería pretencioso creer en la excepcionalidad humana - dejando de lado la creencia en la supremacía humana -, al no aceptar que, por definición, cualquier criatura experimenta el mundo como un desafío desde el momento en el que busca su lugar, lo cual en el fondo impulsará su deseo de vivir. En otras palabras, la capacidad de experimentar el mundo como un desafío no es "el rasgo humano más fundamental" sino que es uno de los rasgos más importantes de cualquier ser viviente. En este sentido, se debe reemplazar algunas formas muy limitadas del antropocentrismo con formas del vitalismo existencialmente inclusivas. ${ }^{137}$

Desde este punto de vista, la siguiente afirmación es problemática:

Lo que es únicamente humano es el impulso original que nos lleva a realizar juegos: divertirnos, socializar, crear e implementar reglas, mejorarlas, etc. ${ }^{138}$ 
El Homo sapiens podría ser concebido como un Homo ludens ${ }^{139}$. Ciertamente, es importante tomar en cuenta nuestra naturaleza lúdica, incluyendo nuestro potencial para ser creativos que se realiza en nuestras formas de acción humana más habituales. ${ }^{140}$ Pero también se debe reconocer que otras especies - incluyendo a los delfines y chimpancés ${ }^{141}$ tienen maneras creativas y lúdicas de relacionarse y actuar con el mundo.

Trascendental vs. inmanente: Al abordar el pensamiento de Kant sobre "el escándalo de la razón", Chernilo realiza la distinción entre "preguntas trascendentales sobre la existencia de Dios, y la posibilidad de la vida después de la muerte, y las preguntas inmanentes sobre cómo se puede manejar la voluntad propia"142. Esta distinción está lejos de no ser controvertibles. Las preguntas sobre la vida, la muerte y los poderes divinos podrían ser consideradas una parte inmanente de la condición humana. Al mismo tiempo, las interrogantes sobre el curso de la vida, los procesos de decisión individual y colectiva, y la imposibilidad de la libre voluntad se podrían tomar como desafíos trascendentales, cuya presencia y relevancia sobrepasa el efímero alcance de las formas de vida delimitadas espaciotemporalmente. Dicho de otra manera, la inmanencia de la trascendencia y la trascendencia de la inmanencia yacen en el corazón de la condición humana.

Científico vs. filosófico: La distinción entre "lo científico" y "lo filosófico" es crucial en el análisis de Chernilo. En sus palabras, "el proyecto de una sociología filosófica opera en un contexto contemporáneo, en el cual las preocupaciones filosóficas ya no son independientes de las científicas"143. El problema de esta afirmación es que falla al asumir que las preocupaciones filosóficas jamás han sido independientes de las 
científicas. Desde los inicios de su camino evolucionario, el Homo sapiens se ha distinguido a sí mismo de otras criaturas como especies sapientes. La ciencia es el intento sistemático de generar conocimiento sobre la base de descripciones, análisis, interpretaciones y explicaciones verificables de algunos aspectos particulares del universo. La filosofía provee el escenario discursivo para el cual la revisión a profundidad de ciertas preguntas fundamentales - notablemente aquellas relacionadas con la naturaleza del ser, del conocimiento, de la moralidad, de la lógica y de la estética. Desde que se inició la etapa histórica, nos hemos embarcado en un viaje evolutivo como entidades que generan y se encuentran en busca de conocimiento. Incluso a pesar del nivel de desarrollo de los estándares epistémicos en las antiguas formas de vida humana y las civilizaciones tempranas, la ciencia y la filosofía han estado íntimamente interrelacionadas desde su nacimiento.

Chernilo acierta al insistir que "no es suficiente que la filosofía acepte que efectivamente ha perdido su posición de privilegio con respecto al conocimiento científico". ${ }^{144}$ A ello se debería añadir que, para algunos, en la historia de las investigaciones humanas, la relación entre las dos siempre ha girado alrededor de la otra: la ciencia, debido a su carácter empírico y su capacidad para llevar a cabo desarrollos tecnológicos, siempre ha tenido una posición de privilegio por sobre el carácter especulativo de la filosofía. Independientemente de la interpretación de esta rivalidad epistémica, a ello no sigue la reflexión de que la filosofía debe "explicar filosóficamente cómo se ha desarrollado la debacle de sus propios enunciados de conocimiento" 145 . De hecho, se podría hacerlo de ambas maneras: filosófica y científicamente. La validez epistémica de los enunciados de la filosofía siempre ha estado, y seguirá estando, íntimamente interrelacionada con aquellos que han generado iniciativas científicas. 
En lugar de lamentarse por "la inhabilidad de la sociología europea por diferenciarse, por un lado, entre preocupaciones filosóficas/normativas, y por el otro, de las estrictamente científicas/empíricas"146, se necesita aceptar su profunda interdependencia e interpenetración. Más aun, es necesario no mantener una supuesta relación necesaria entre (1) "lo normativo" en conjunto principal o exclusivamente con "lo filosófico" y (2) "lo empírico" principal o exclusivamente con "lo científico". Las indagaciones científicas se encuentran permeadas por supuestos, principios, convenciones y estándares normativos - de hecho, estas indagaciones podrían servir para definir a los últimos. Las indagaciones filosóficas, por otra parte, hacen uso de hechos, consideraciones, estudios y hallazgos empíricos - de hecho, las indagaciones filosóficas, a medida que se acoplen con el mundo "real", están permeadas por las investigaciones empíricas. La imagen que se genera, entonces, es mucho más compleja y amorfa de la que Chernilo aparentemente sugiere.

Actores ordinarios "intra-existenciales" vs. expertos "metaexistenciales": Parecería que Chernilo asume que la práctica de preguntarse sobre "las grandes preguntas" - especialmente en relación con la naturaleza de los seres humanos y el significado de la vida - es más común entre los expertos que entre los actores ordinarios.

(...) mientras que la pregunta sobre "qué es un ser humano" usualmente no se realiza de parte de los individuos por su propia cuenta (con excepción de los intelectuales profesionales, quienes lo hacen en su capacidad de "expertos"), las preguntas sobre Dios, la libertad, la inmortalidad son interrogantes clave sobre el "significado de la vida" en sus dimensiones trascendentales e inmanentes. ${ }^{147}$ 
Esta visión es problemática en al menos dos aspectos: por un lado, está viciada empíricamente, pues las personas ordinarias efectivamente lidian con "las grandes preguntas" (incluso, se podría argumentar que lo hacen con más frecuencia que la que a Chernilo le gustaría admitir), no sólo cuando se enfrentan a desafíos y dilemas existenciales; por otro lado, está viciada normativamente, pues bosqueja la vida cotidiana como un asunto ampliamente no-reflexivo, en el cual los principales participantes, debido a cierta falta de capacidad crítica y de curiosidad intelectual, se encuentran atrapados en una nube de percepciones equivocadas, malas interpretaciones y representaciones erróneas dóxicas. La vida social es siempre ya (immer schon) un asunto intra- y meta-existencial - para quienes la estudian, y también para quienes la construyen y experimentan.

Descriptivo vs. normativo: A lo largo de su estudio, Chernilo realiza una distinción entre "lo descriptivo" y "lo normativo". En el contexto de su investigación, esta separación conceptual es problemática por algunas razones.

Como subraya Chernilo en su interpretación de Arendt sobre las "descripciones normativas"148, la distinción mencionada previamente es cuestionable, pues estos dos niveles de desarrollo epistémico están inevitablemente ligados. Basándose en Arendt, Chernilo brinda un ejemplo ilustrativo (esto es, que un campo de concentración es un "infierno en la tierra"149). De todos modos, él no acepta, en sentido estricto, que todas las descripciones tengan un carácter normativo, implícito o explícito. Este hallazgo normativo nos obliga a reflexionar en la contingencia social relacionada con la producción, circulación y consumo de todo el conocimiento: 
En primer lugar, dado que el conocimiento siempre está socialmente arraigado, entonces necesariamente es normativo. En segundo lugar, puesto que el conocimiento siempre se genera desde una posición específica del espacio social, incluso el llamado conocimiento descriptivo es situacional (Erkenntnisstandpunkt). Tercero, en la medida que los actores toman roles particulares en la sociedad, dejando de lado si se trata de expertos u actores ordinarios, el conocimiento está permeado relacionalmente por las funciones ejercidas por aquellos que hacen uso de tal conocimiento, de acuerdo con sus intereses definidos contextualmente (Erkenntnisfunktion). Cuarto, considerando que los actores cognitivos son entidades en competencia discursivamente, la producción de conocimiento está permeada por luchas de poder científico (Erkenntniskampf). Quinto, por motivo de que los motivos simbólicos e informacionales pueden ser utilizados de maneras distintas y para múltiples objetivos, la producción de conocimiento puede ser instrumentalizada para propósitos extra-científicos - notablemente económicos (Erkenntnisnutzung). En resumen, la apuesta positivista por la objetividad pierde credibilidad cuando se confronta con la constitución relacional de la investigación epistémica. Las condiciones de cognoscibilidad están impregnadas de normatividad, posicionalidad, conflictualidad e instrumentalidad. ${ }^{150}$

IV. Como se muestra en secciones precedentes, es problemática la idea de que "una descripción normativa coherente yace sobre tres compromisos básicos"151: una concepción universalista de humanidad, una concepción evaluativa de normatividad, y una concepción crítica de las ciencias sociales. Lo que es evidente en la justificación de estos compromisos es que se enfoca en las "descripciones normativas" al nivel abstracto de los 
discursos intelectuales, académicos, científicos e institucionales, más que al nivel concreto de la vida cotidiana. Críticos menos comprensivos podrían objetar que una concepción abstracta de normatividad es "blanca, masculina y vieja" - esto es, que está ampliamente desconectada de la heterogeneidad, diversidad y complejidad de la vida cotidiana de la gente, sobre los distintos sectores de la sociedad.

V. Como sujetos capaces de hablar, reflexionar y actual, estamos aptos para producir numerosos tipos de conocimiento:

1 como seres representacionales, estamos aptos para producir conocimiento descriptivo;

2 como seres analíticos, construimos conocimiento sistemático;

3 como seres reflexivos, somos capaces de desarrollar conocimiento explicativo;

4 como seres críticos, generamos conocimiento normativo;

5 como seres comunicativos, participamos en el intercambio de conocimiento discursivo;

6 como seres con la capacidad de aprender, nos construimos sobre conocimiento cumulativo;

7 como seres proyectivos, podemos realizar suposiciones sobre el futuro en base a conocimiento predictivo. ${ }^{152}$

Si nos enfocamos exclusivamente en los aspectos descriptivos y normativos de la producción de conocimiento humano (incluso si se reconoce su interrelación), entonces fallamos al dar cuenta de la multiplicidad de formas de poder de sus funciones. Los actores humanos pueden desarrollar muchos tipos de conocimiento, cuando se envuelven con el mundo de alguna manera propositiva, comunicativa, discursiva y/o creativa. 
Universal(ista) vs. particular(ista): Chernilo afirma que un "principio universalista de humanidad se prefiere sobre concepciones particularistas de raza, cultura, identidad y clase" 153 . Desde este punto de vista, el primero trasciende las contingencias agenciales y estructurales de las últimas. Una postura universalista, entonces, insiste en que nuestras características distintivas como especie son el fundamento más fiable y confiable para justificar argumentos normativos. Como miembros de una misma especie, buscamos intereses humanos que son, por definición, universalizables. Como individuos y como miembros de grupos diferentes, perseguimos intereses personales y sociales que, paradójicamente, nos unen y nos dividen. Chernilo brinda poca luz al no analizar críticamente el grado en el cual las categorías "particularistas" (incluyendo aquellas que menciona) pueden ser invocadas como fundamentos "universalistas" de la emancipación humana incluso si lo hacen de manera correcta o errónea. El trabajo de Marx sobre el conflicto de clases se basa en el supuesto de que, eventualmente, este conflicto va a culminar en la emancipación "humana" o "universal", una vez que emerja una sociedad sin clases. Los fascistas argumentaban que la naturaleza "universalista" de su proyecto se sostenía en el principio natural de la "supervivencia del más fuerte", la cual estaría presente en las luchas por la "supremacía racial y/o nacional". Los proselitistas religiosos piensan y promocionan la naturaleza universalista de su redención. En breve, las metanarrativas ideológicas - incluso si son deconstruidas, esencialmente, como puntos de vista particularistas del mundo - son "universalistas" en el sentido de que manifiesta ser omniabarcativas. ${ }^{154}$ La dicotomía entre el universalismo y el particularismo es más borrosa de lo que Chernilo admite.

Antropológico vs. social: Chernilo defiende que "(1)as características antropológicas que nos definen como seres humanos son, en gran medida, independientes, pero no pueden ser realizadas completamente por fuera de 
la vida social"155 - esto es que son "autónomas con respecto a la sociedad, incluso si su propia actualización es social en sí misma"156. El problema de este supuesto es que, nuevamente, se basa en la errónea dicotomía entre "lo antropológico" y "lo social". Es correcto insistir que nuestras características antropológicas no pueden ser realizadas fuera de la vida social. Pero, de todos modos, se necesita avanzar un paso más, al subrayar que estas características siempre dependen más de la vida social - y viceversa. Podemos enfocarnos en las "características antropológicas" discutidas en este libro: la autotrascendencia, la adaptación, la responsabilidad, el lenguaje, las evaluaciones fuertes, la reflexividad y la reproducción de la vida. Asimismo, se puede tener en cuenta otros elementos que están asociados - sea de manera correcta o errónea - a la condición humana: la cultura, el lenguaje, la consciencia, el autoconocimiento, la moralidad, el juicio estético y la razón - para mencionar algunos. Ninguno de ellos puede ser disociado empírica o históricamente de la vida social. Los primeros deben su propia existencia a los últimos. Así, el "trascendentalismo universalista" de Chernilo brinda poca importancia a la significación de la sociabilidad que permea todas las dimensiones de humanidad que nos constituyen como especie.

\section{¿Miembros promedio?}

Chernilo sostiene que "todo miembro promedio de la especie humana tiene similitudes relacionadas con las capacidades antropológicas generales que realizan una contribución significativa a la vida en sociedad"157. Está lejos de ser claro, por cierto, cómo es posible determinar qué se supone que es un "miembro promedio de la especie humana" -dejando de lado el modo cómo medir el grado en el 
que todos están equipados con ciertas "capacidades antropológicas generales". De hecho, estas capacidades están profundamente formadas por la distribución asimétrica de recursos y poder, lo cual debe su influencia a algunas variables sociológicas decisivas como la clase, etnicidad, género, edad y habilidad.

¿Es menos humana una persona que tiene un limitado acceso a recursos sociales - los cuales, en caso de que estén disponibles, permiten el desarrollo cognitivo, intelectual, emocional, físico, lingüístico y moral - que una persona que está equipada con numerosas formas de capital (como el capital social, cultural, político, educativo, económico, financiero y simbólico)? ¿Es más humana una persona que es "excepcionalmente culta", "extremadamente elocuente", "altamente inteligente" y "siempre guiada por la razón" que una persona que está privada (parcial o totalmente) de este tipo de "capacidades"? ¿Es una persona sin formación, indígena, de sexo femenino, homosexual, de mayor edad, física o mentalmente desaventajada "menos humana" que una persona burguesa, blancoeuropea, de sexo masculino, heterosexual, de menor edad, física y mentalmente sana? Obviamente, la respuesta es no.

El "universalismo antropológico" de Chernilo corre el riesgo de apoyar cierta jerarquía de habilidades deseables y atributos donde "los de arriba" están más cerca del ideal de humanidad "que los de abajo". No se necesita ser un experto en la historia de la eugenesia para comprender los enormes peligros de levantar jerarquías arbitrarias (socialmente construidas) acorde con lo que algunos humanos se encuentran mejor equipados de "capacidades antropológicas generales" que otros. 
¿Cosmopolitismo imaginario vs. tribalismo del mundo real?

En un tono universalista, Chernilo afirma que "los seres humanos reconocen a otro como miembros de la misma especie porque estos legados antropológicos compartidos"158. En defensa de Chernilo, esta afirmación es precisa, en un sentido realista y en un sentido normativista:

En un sentido realista, es precisa porque los humanos son actores que no pueden construir una sociedad a menos que se reconozcan a sí mismos como criaturas que pertenecen a la misma especie y que comparten cierta cantidad de características fundamentales, incluso si lo hacen implícita y/o inconscientemente. Por ejemplo, cuando sujetos capaces de lenguaje y de acción se comunican lingüísticamente (esto es, manifestándose a través de reivindicaciones de validez sobre la base de los recursos morfológicos, semánticos, sintácticos, gramáticos, fonéticos y pragmáticos de su lenguaje), ellos presuponen que aquellos envueltos en este proceso están equipados de los legados antropológicos necesarios para funcionar como miembros aceptados en una comunidad de habla.

En un sentido normativista, es precisa, porque es en vano pensar en formas de emancipación individuales o colectivas, a menos que se asuma que todos los humanos comparten una cierta cantidad de características constitutivas como especie, hacia las cuales se hace referencias explícitas y/o conscientes, especialmente en momentos de conflicto por ideas o ideales universal(istas) - como la justicia, la dignidad, la democracia y la "buena vida". Por ejemplo, cuando algunos sujetos capaces de lenguaje y de acción están temporal o permanentemente privados del derecho a comunicarse con otros lingüísticamente, ellos desafiarán los mecanismos discriminatorios que los han llevado hacia su exclusión al insistir en su estatus de miembros de la humanidad en general, y de una comunidad de habla en particular. 
Independientemente del valor del argumento realista o normativista de Chernilo, él sobreestima la fuerza (universalista) del cosmopolitismo y subestima la fuerza (particularista) del tribalismo. El sentido de conexión de las personas con grupos sociales particulares - expresados en defensa implícita o explícita de sus identidades tribales - usualmente es más poderoso, tangible y decisivo que su sentido de pertenencia a una noción de humanidad relativamente abstracta. Las afiliaciones tribales con grupos sociales particulares (definidos por la clase, etnicidad, género, edad, habilidades y/u otras importantes variables sociológicas) pueden actuar de igual modo como una fuerza divisoria o de vinculación: así como proveen un sentido de pertenencia e inclusión (en relación con los "insiders"), promueven un sentido de demarcación y exclusión (en relación con los "outsiders").

Cabe considerar, nuevamente, el ejemplo de las comunidades de habla: Las comunidades de habla están divididas internamente (esto es, dentro de lenguajes específicos) por el poder estratificador de cruciales variables sociológicas (como la clase, etnicidad, género, edad, habilidad, etc.). Estas divisiones están reflejadas en jerarquías de legitimidad, reproducidas por patrones socialmente definidos de inteligibilidad y sostenidos por el juego tríadico mutuo de campos, habitus y capital (lingüísticos). ${ }^{159}$

Las comunidades de habla están divididas externamente (esto es, entre distintos lenguajes) por el poder estratificador del lenguaje en sí mismo. Diferentes lenguajes se basan en diferentes reglas y estándares (morfológicos, semánticos, sintácticos, gramáticos, fonéticos y pragmáticos). ${ }^{160}$

Dada su función social (en términos de proveer un sentido de pertenencia y cohesión) y su función interpretativa (como la "morada del ser" que brinda un "tesoro de significación"), no es un accidente que el lenguaje 
sea, a la vez, una fuerza divisoria o de vinculación: nos podemos relacionar con aquellos que hablan el mismo lenguaje - como nosotros -, pues a través de ellos se brinda significado al mundo hermenéuticamente; pero no nos podemos relacionar (o difícilmente podríamos hacerlo) con aquellos que no hablan el mismo lenguaje que nosotros, pues no compartimos su horizonte de sentido culturalmente codificado y simbólicamente mediado. ${ }^{161}$

La misma dialéctica de la universalidad y la particularidad aplica a todas las demás características antropológicas - incluyendo la cultura, el sentido de la existencia, la autoconsciencia, la moralidad, el juicio estético y la razón. En breve, la esfera de los atributos antropológicos es tanto un reino trascendente de lo que nos constituye como especie como una esfera contextual de las particularidades que nos dividen.

\section{¿Confusión disciplinaria?}

Algunas afirmaciones que hace Chernilo en relación con las disciplinas académicas en cuestión son un tanto confusas. Por ejemplo, no es preciso argumentar que, durante el predominio intelectual de Husserl en Alemania, "la antropología filosófica era vista como una filosofía de segundo grado"162. Si de algún modo habría de ser considerada, seguramente sería como una "antropología de segundo grado" (con un fuerte componente filosófico). En un sentido similar, críticos poco comprensivos podrían rechazar el proyecto de una "sociología filosófica" como una "sociología de segundo grado" o como una "sociología abstracta" (con un fuerte componente filosófico).

De manera más sustantiva, se podría preguntar en qué medida podría también ser prometedor emprender el proyecto de una "filosofía sociológica". Indudablemente, la "filosofía social" y la 
"filosofía política" son áreas muy bien establecidas de investigación, pues se basan en la sociología (notablemente, en la teoría social) y en las ciencias políticas (sobre todo, en la teoría política). Sería difícil identificar una gran cantidad de académicos que se definan a sí mismos como "filósofos sociológicos". La mentalidad de guardianes compartida por algunos filósofos (pero, sin duda, no todos) expresa una actitud disciplinaria que muestra poco interés intelectual por las herramientas conceptuales de una disciplina empírica como la sociología.

En estricto sentido, se podría argumentar que ambas etiquetas - a saber, "sociología filosófica" y "filosofía sociológica - son tautológicas: no es posible realizar una investigación sociológica seria, a menos que se encuentre informada por reflexiones filosóficas sobre la naturaleza del ser, del conocimiento, de la moralidad, de la lógica y de la estética; de igual modo, no existe una comprehensiva investigación filosófica a menos que tome en cuenta hallazgos sociológicos, en la medida en que todas las formas de vida están moldeadas socialmente por prácticas, estructuras y constelaciones contingentes.

¿Qué se puede decir, entonces, sobre el rol de homo sociológicos, homo oeconomicus y homo psicologicus?

Concebir al homo sociologicus ${ }^{163}$, ante todo, como una criatura "con un comportamiento estable y predecible por los roles que lo conforman"164 no requiere dejar de lado la posibilidad de "describir la naturaleza del hombre de manera precisa y realista" - como asume Chernilo al referirse a Dahrendorf. ${ }^{165}$

La noción de que el homo oeconomicus ${ }^{166}$ se orienta, sobre todo, según el "cálculo de posibilidades de ganancia personal" 167 basado en decisiones racionales es problemática, pues deja de lado el hecho de 
que numerosas ramas en la economía (especialmente aquellas que se basan en la sociología y la psicología social) reconocen que el comportamiento humano está profundamente influenciado por factores sociales.

Asociar al homo psicologicus ${ }^{168}$, principalmente, con el estudio de los "motivos inconscientes"169 es incorrecto en la medida en que este enfoque de investigación sólo se comparte por algunos psicólogos (notablemente psicoanalistas), pero, de ninguna manera, por todas las ramas de la psicología.

Estudios interdisciplinares del homo sociologicus, homo oeconomicus y homo psicologicus apuntan a comprender "el punto particular en el cual el individuo y la sociedad se intersectan"170. Es reduccionista sugerir que "ninguno ofrece una teoría de la naturaleza humana comprehensiva, sino que, al contrario, se construyen sobre una exageración unilateral de una característica antropológica particular, que es particularmente útil, desde un punto de vista disciplinario, que es igualmente particular"171.

Ciertamente, se ha vuelto poco popular defender la noción de que existe alguna cosa tal como la "naturaleza humana". Efectivamente, numerosas tradiciones intelectuales en las humanidades y las ciencias sociales - notablemente constructivistas, perspectivistas, deconstruccionistas, posmodernistas, posestructuralistas, postcolonialistas y feministas - rechazan toda idea de una "naturaleza humana", especialmente porque podría ser usada (o ha sido usada) como una arma ideológica de dominación social para legitimar las inequidades sociales, especialmente aquellas basadas en la "clase", la "raza", el "sexo", la "edad" y las "habilidades".

De todos modos, las disciplinas previamente mencionadas - esto es, la sociología, economía y psicología - han producido concepciones 
fundacionales de la naturaleza humana dentro de las grandes corrientes de pensamiento (como el marxismo, funcionalismo, evolucionismo, racionalismo, estructuralismo, etc.). Estas lo han hecho, en buena medida, al nutrirse de conocimiento de áreas de investigación cercanas entre sí. Por supuesto, Chernilo acierta al enfatizar que toda disciplina tiende a enfocarse (e incluso, a exagerar) algunas presuposiciones epistemológicas y ontológicas clave que sostienen su horizonte de investigación específico a su disciplina. No obstante, otras disciplinas no lo hacen al señalar múltiples ámbitos de conocimiento $\mathrm{y}$, en consecuencia, al trascender ciertos límites epistemológicos que las conforman. Una razón para ello es que las respuestas comprehensivas (y remotamente satisfactorias) a "las grandes preguntas" sólo pueden ser desarrolladas en varias disciplinas. Otra razón de esto es que las tradiciones intelectuales más prominentes están insertas y se desarrollan dentro de diversos marcos de referencia disciplinarios y subdisciplinarios (coexistentes y competitivos).

\section{¿La humanidad "anormativa" de Bourdieu?}

En relación con el trabajo de Bourdieu, Chernilo enuncia al menos tres argumentos que merecen ser examinados.

I. Plantea que Bourdieu "no conceptualiza la normatividad sociológicamente" 172 y que las "ideas normativas no están incluidas como una dimensión efectiva del mundo social porque el conflicto y las luchas de poder son suficientes para una ontología completamente formada de lo social" 173

II. Declara que Bourdieu pone en marcha "una noción reduccionista de interés individual en un nivel antropológico"174, el cual se encuentra atado 
con una "concepción igualmente reduccionista de lo social como un espacio de constante lucha" ${ }^{175}$.

III. Sostiene que Bourdieu se encuentra atrapado en una "concepción irracionalista de naturaleza humana"176, la cual "refleja los argumentos unilaterales ofrecidos sobre la autenticidad primordial"177.

Desde su punto de vista, Bourdieu es culpable de refrendar (1) una representación "“anormativa" de la vida social"178, (2) una comprensión reduccionista de lo social en general y del interés individual en particular, así como (3) una interpretación "irracionalista" y unilateral de la naturaleza humana. Esta lectura del trabajo de Bourdieu, en todo caso, se podría enfrentar con los siguientes argumentos:

I. Bourdieu conceptualiza la normatividad sociológicamente; su enfoque incluye ideas normativas como dimensión efectiva del mundo social; el conflicto y las disputas de poder no se consideran suficientes para una ontología de lo social enteramente formada. De hecho, los conceptos de illusio, doxa y poder simbólico de Bourdieu - por no mencionar sus escritos sobre la ideología - indican claramente una importante preocupación no sólo por el rol central que tiene la normatividad en la construcción de la vida social, sino también por la constitución multinivel de la existencia humana. Bourdieu podría sobreestimar la importancia del conflicto y las luchas de poder, apuntando hacia una forma de fatalismo socio-ontológico. Esto no significa, por lo tanto, en que falla al presentar un rico análisis de la normatividad en sus escritos - especialmente en relación con las formas simbólicas. ${ }^{179}$

II. La concepción del interés (individual) de Bourdieu es más compleja de lo que Chernilo sugiere, a pesar de que existan buenas razones para cuestionar su validez. De acuerdo con Bourdieu, los agentes tienen (y persiguen) una multiplicidad de intereses, de acuerdo con la multiplicidad de 
campos sociales en los cuales se encuentran inmersos: culturales, políticos, educacionales, económicos, lingüísticos, etc. - por mencionar sólo algunos. En la medida en que Bourdieu plantea que, en el fondo, toda acción social no sólo está motivada por la búsqueda del poder y de los intereses sino también dirigida por la búsqueda del poder y de los intereses, su ontología social es, efectivamente, reduccionista. Por otra parte, a medida que provee una visión policéntrica (si no descentrada) de múltiples campos de competición, su ontología es multifacética. ${ }^{180}$

III. Debido a su crítica radical del esencialismo biológico, Bourdieu no asume cualquier concepción de la "naturaleza humana", al menos no explícitamente. Se podría objetar que, efectivamente (léase, implícitamente), se suscribe a una noción fatalista de la "naturaleza humana", en la medida en que enmarca a la vida social como un conglomerado de campos sociales que equivalen a "juegos sociales", moldeados por la lucha constante por el acceso a las formas de capital y recursos vitales. ${ }^{181}$ Esto no justifica el enunciado de que permanece atrapado en una concepción "irracionalista" de la naturaleza humana.

En breve, la lectura de Chernilo del trabajo de Bourdieu, la cual lo acusa esencialmente de reduccionismo, es reduccionista en sí misma. Es cierto que la "sociología crítica" de Bourdieu ${ }^{182}$, a diferencia de la "sociología de la crítica" de Boltanski ${ }^{183}$, privilegia la autoridad epistémica de los científicos y los expertos sobre las personas ordinarias, preparando el camino para la "distopia de la sociología que acarrea su propio cumplimiento"184 y una visión fatalista de la vida cotidiana. ${ }^{185}$ Esta limitación substancial no significa, por otra parte, que desde una perspectiva bourdieuseana, la vida social es esencialmente "anormativa". 


\section{¿Entre el universalismo y el constructivismo?}

Basándose en Michel Foucault ${ }^{186}$, Chernilo enuncia que "(1)as ideas de la humanidad están socialmente construidas, cambian históricamente y contienen supuestos altamente problemáticos a nivel cognitivo, teológico y normativo"187. En todo caso, no explica de manera convincente cómo es posible reconciliar el constructivismo social con el universalismo normativo que yace bajo su argumento. Si los derechos humanos están construidos socialmente, entonces no pueden ser universalmente vinculantes y sus defensores no podrían defender seriamente su validez intercultural, y menos una su independencia contextual. Se puede respaldar una concepción constructivista/contextualista o una concepción universalista/fundacionalista de los derechos humanos, pero no ambas. Acertadamente, Chernilo critica a los posthumanistas por su error al "articular sus posiciones normativas, pues no son capaces de clarificar cuál (...) es el núcleo humano que están dispuestos a apoyar"188. Si pretendemos señalar una posición normativa basándonos en un terreno constructivista únicamente, entonces los criterios utilizados son categóricamente no-categóricos y, por lo tanto, altamente arbitrarios. Los imperativos categóricos podrían ser categóricamente nocategóricos, pues son contingentes dependiendo de los distintos criterios y circunstancias que los definen de manera normativa y subjetiva. Sin embargo, si se desea adherirse a un punto de vista constructivista, entonces no hay mucho espacio disponible - si es que lo hubiese - para perseguir cierto tipo de universalismo normativo viable. 
¿Nuestra humanidad (no) compartida?

Chernilo afirma que "nuestra humanidad compartida se ha vuelto cada vez más importante (y desafiante también) para los humanos" 189 . El problema con esta afirmación es la naturaleza tautológica del concepto de "humanidad común". Si la humanidad es lo que todos los miembros de nuestra especie tienen en común, entonces esta es, por definición, compartida. En estricto sentido, no hay tal cosa como una "humanidad no-compartida".

Otro problema es el tema de la (in)equidad que nos constituye como especies. Los cínicos podrían declarar, provocativamente, que mientras algunos son más "iguales" que otros, algunos son más "humanos" que los demás. En otras palabras, un importante problema surge al identificar un conjunto de "características antropológicas" (como la cultura, el lenguaje, la conciencia, el autoconocimiento, la moralidad, el juicio estético y la razón) que podrían estar más presentes con unos que con otros.

Con ello, se vuelve al problema previamente mencionado de las jerarquías inventadas en términos de los distintos grados de "capacidades antropológicas generales". Finalmente, ¿será que nuestra "humanidad compartida" es realmente más importante y desafiante para nosotros ahora que solía ser el caso para generaciones anteriores, como las de 1789, $1848,1914,1918,1933,1939,1945,1986$ o 1989/1990? Es cierto que el cambio climático y la posibilidad de la destrucción nuclear global presentan desafíos en escalas sin precedentes. Sin embargo, en vez de sobreestimar su relevancia actual, se debería reconocer que nuestra "humanidad compartida" ha sido una preocupación central en otros capítulos de la historia humana. 
Lo humano, lo social y lo normativo: ¿entre el optimismo y el pesimismo?

Acertadamente Chernilo insiste que "nuestras concepciones de lo humano fundamentan nuestras nociones normativas de la vida social" 190 . No es menos importante admitir al mismo tiempo que nuestras nociones normativas en la vida social fundamentan nuestras concepciones de lo humano. Una concepción optimista de lo humano puede encontrarse debajo de una noción romántica de la vida social, y viceversa. Al mismo tiempo, una concepción fatalista de la vida social puede ocultarse en una concepción pesimista de la vida social, y viceversa.

Se podría considerar a algunas de las mayores ideologías políticas de la era moderna como ejemplos. Los seguidores del anarquismo, comunismo y socialismo tienden a concebir a los humanos como seres cooperativos, altruistas y relativamente maleables. Los conservadores, por el contrario, tienden a bosquejar a los humanos como competitivos, egoístas y poco maleables. La primera concepción de lo humano (optimista) se refleja en la creencia de que es posible construir una sociedad que esté ampliamente - si no enteramente - libre de mecanismos de explotación, exclusión y dominación. La última concepción de lo humano (pesimista) se ilustra como el dictamen de que un Estado fuerte es necesario para asegurar que la ley, el orden y las instituciones sociales garanticen que las acciones de los individuos estén guiadas por cierto sentido del deber y responsabilidad con "su nación".

También se pueden considerar los marcos explicativos más importantes de las disciplinas académicas en relación con la constitución de la existencia humana. Los propulsores del constructivismo social asumen que los 
humanos son, en buena medida, productos de sus entornos socioculturales. Los creyentes del determinismo biológico, por otra parte, suponen que los humanos están, amplia o enteramente, determinados por su constitución genética. La primera concepción de lo humano (optimista) se expresa al afirmar que las personas pueden desarrollarse y emanciparse, en la medida en que las correctas condiciones sociales les permitan hacerlo desde su posición. La última concepción de lo humano (pesimista - o, como otros argumentarían, realista) se articula bajo el sustento de que las personas están equipadas con un conjunto de predisposiciones genéticamente determinadas, las cuales determinan el alcance de sus prácticas - incluso, a pesar de que su desarrollo es contingente sobre la base de sus variables condiciones espaciotemporales.

En breve, así como nuestras concepciones de lo humano soportan nuestras nociones normativas de la vida social, nuestras nociones de la vida social se encuentran debajo de nuestras concepciones de lo humano. El proyecto de Chernilo subestima el grado en el que la normatividad es un elemento central, y no periférico, de la existencia social:

La sociología filosófica no afirma que la normatividad sea el centro de la vida social, pero sostiene que la vida social no podría ser analizada sin este tipo de orientación normativa explícita. ${ }^{191}$

Las orientaciones normativas forman una parte importante de los intentos científicos para estudiar distintos aspectos de la vida social, pues son parte de la vida social en sí misma. De hecho, hay un componente constitutivo de las formas de vida social, pues todas las prácticas, estructuras y órdenes sociales están codificados culturalmente. De este modo, están permeadas contextualmente por estándares normativos cambiantes. Los estudios sociológicos de las actividades humanas más comunes (como pensar, caminar, 
hablar, comer, dormir, lavarse, adentrarse en un encuentro sexual, etc.) demuestran que la normatividad se encuentra en el corazón de la vida humana.

Posiblemente, Chernilo es culpable de un romanticismo socio-ontológico al sugerir que se puede evaluar la calidad de las formas de sociabilidad del comportamiento, ideológicas e institucionales a través del grado en el que promueven u obstruyen "el desarrollo de nuestro potencial humano genérico" 192. Este es, sin lugar a duda, un ideal noble, pero debemos aceptar también que hay potenciales humanos generales que son destructivos y malignos, y no sólo productivos y emancipatorios. Chernilo tiende a sobreestimar la importancia de estos últimos y dejar de lado los primeros. Así como se necesita generar formas de sociabilidad ideológicas, institucionales y conductuales que promuevan el desarrollo de unos, se necesita crear condiciones históricas que impidan el desarrollo de los otros. Una visión realista de la vida social se enfrenta al hecho de que un conjunto de profundas tensiones normativas se construye dentro de la condición humana - como el bueno vs. el malo, cooperativismo vs. competitividad, altruismo vs. egoísmo, pacíficismo vs. violencia, serenidad vs. agresividad, amigabilidad vs. beligerancia, racionalidad vs. impulsividad. ${ }^{193}$ No se puede simplemente señalar los "potenciales humanos genéricos" que se encuentran al abordar los fundamentos normativos de la sociología filosófica desde los fundamentos ontológicos de la humanidad. También es necesario incluir aquellos "potenciales genéricos humanos" que exponen el lado oscuro de la humanidad, si lo que se busca es desarrollar una noción verdaderamente comprehensiva de la normatividad, capaz de dar cuenta de la naturaleza de la sociedad basada en este tipo de tensiones. ${ }^{194}$ 


\section{Conclusión}

Debating Humanity es una importante contribución al pensamiento social y político contemporáneo. El intento de Chernilo de desarrollar un bosquejo de una "sociología filosófica" es un valioso esfuerzo, especialmente en un momento en el que se ha vuelto cada vez más impopular defender concepciones universalistas de lo humano - en particular, debido a la amplia influencia de los enfoques socioconstructivistas sobre las humanidades y las ciencias sociales (especialmente aquellos asociados con el postmodernismo, postestructuralismo, postcolonialismo, feminismo e interseccionalismo). Varias dimensiones del argumento de Chernilo son altamente perspicaces y profundas; otras dimensiones de su argumento, no obstante, son problemáticas y debatibles. Dejando de lado sus limitaciones y aspectos controvertibles, el estudio de Chernilo es un poderoso recordatorio de que un entendimiento verdaderamente comprehensivo de la sociedad requiere un compromiso crítico con el concepto de humanidad.

\section{Notas al final}

\footnotetext{
${ }^{1}$ Chernilo (2017). En mi análisis, me enfocaré en la Introducción (pp. 1-22) y el Epílogo (pp. 229-236), pues proveen un útil resumen general de los principales argumentos que sostienen el estudio de Chernilo. Cf. Guhin (2019).

${ }^{2}$ Cf. Chernilo (2014). Adicionalmente, cf. Chernilo (2013).

${ }^{3}$ Chernilo (2017), p. 1 (itálicas añadidas).

${ }^{4}$ Ibid., p. 1 (itálicas en el original).

${ }^{5}$ Ibid., p. 1 (itálicas en el original).

${ }^{6}$ Ibid., p. 1.

7 Sobre este punto, se puede revisar ibid., p. 2. Cf. también, por ejemplo: Adorno (2000 [1993]); Cordero (2017), pp. x, 7-8, 11, 153, 155, 160, 161n27 y 162; Manent (1998 [1994]); Susen (2017a), pp. 102-103 y 108-109.
} 
${ }^{8}$ Chernilo (2017), p. 2 (itálicas en el original).

${ }^{9}$ Revisar, por ejemplo: Durkheim (1964 [1960]); Durkheim (1982 [1895]); Durkheim (2010 [1951/1953]). Cf., adicionalmente: Gane (1988); Giddens (1978); Lukes (1973); Susen (2015a), pp. 48-63. 10 Chernilo (2017), p. 2 (itálicas en el original). Cf. Susen (2016b).

${ }^{11}$ Revisar Chernilo (2017), p. 2. También, por ejemplo: Benton (1977); Benton y Craib (2001), pp. 13-49; Susen (2015a), pp. 48-63.

12 Revisar, por ejemplo: Weber (1978 [1922]); Weber (1991 [1948]); Weber (2001/1930 [1904-05]). También: Albrow (1990); Baert (2005); Susen (2016b); Turner (1992); Whimster (2001).

13 Chernilo (2017), pp. 2-3 (itálicas en el original). También se puede revisar Ginsberg (1968) y Hughes (1974).

${ }^{14}$ Revisar, por ejemplo: Marx (2000/1977 [1845]); Marx (2000/1977 [1859]).

15 Se puede revisar Chernilo (2017), pp. 2-3. También, por ejemplo: Habermas (1988 [1963]); Marcuse (2000 [1941/1955]).

${ }^{16}$ Como por ejemplo en: Butler (1990); Walby (2011).

17 Tentativamente en: Bhambra (2014); Go (2016).

18 Como referencia: Chernilo (2017), pp. 2-3. Revisar también: MacIntyre (1981); Nisbet (1967).

${ }^{19}$ Chernilo (2017), p. 3 (itálicas en el original).

${ }^{20}$ Sobre este punto, revisar ibid., pp. 3-7. Adicionalmente: Borsari (2009); Fischer (2009); Gebauer y Wulf (2009); Rehberg (2009). En este marco, de todos modos, Chernilo se fundamente principalmente en Cassirer (1972 [1923/1925/1929]) y Schnädelbach (1984 [1983]).

${ }^{21}$ Chernilo (2017), p. 4.

22 Ibid., p. 4.

${ }^{23}$ Ibid., p. 4 (itálicas en el original). Cf. Blumenberg (2006).

${ }^{24}$ Ver Chernilo (2017), pp. 4-5.

${ }^{25}$ Se hace referencia a ibid., p. 5. Cf. Löwith (1993 [1932]).

${ }^{26}$ Chernilo (2017), pp. 7-10. También, por ejemplo: Dahrendorf (1965); Dahrendorf (1968 [1965]); Dahrendorf (1968), ver esp. su ensayo sobre 'La sociología y la naturaleza humana'.

${ }^{27}$ Revisar Chernilo (2017), pp. 7-10.

${ }^{28}$ Ibid., p. 8.

${ }^{29}$ Ibid., p. 8.

${ }^{30}$ Ibid., p. 9.

${ }^{31}$ Ibid., p. 9.

${ }^{32}$ Ibid., p. 9.

${ }^{33}$ Ibid., p. 9 (itálicas en el original).

${ }^{34}$ Ibid., p. 10 (itálicas añadidas).

35 Ibid., p. 10.

36 Ibid., p. 10.

${ }^{37}$ Revisar ibid., pp. 10-18. También: Badmington (2000); Braidotti (2013); Braidotti (2019); Fukuyama (2002); Hayles (1999); Herbrechter (2013 [2009]); Hollis (2015 [1977]); Mahon (2017); Nayar (2014); Peterson (2018); Taylor (1989).

${ }^{38}$ Chernilo (2017), p. 11.

${ }^{39}$ Revisar, tentativamente: Archer (2000); Atanasoski y Vora (2019); Habermas (2003 [2001]); Fuller (2011); Fuller (2013); Fuller y Lipińska (2014); Honneth y Joas (1988 [1980]); Pinker (2002); Pinker (2018); Scheler (2009 [1928]); Sloterdijk (2009); Steane (2018); Wilson (2004 [1978]).

${ }^{40}$ Chernilo (2017), p. 11.

${ }^{41}$ Como por ejemplo en: Latour (1990); Latour (1993 [1991]); Latour (2005); Latour (2013 [2012]). 
${ }^{42}$ Revisar, por ejemplo: Braidotti (2013); Braidotti (2019).

43 Por ejemplo: Clark (2001); Clark (2008).

${ }^{44}$ Revisar Chernilo (2017), p. 12.

${ }^{45}$ Sobre este punto, ibid., p. 11. Una referencia similar se puede encontrar en Latour (2013 [2012]), pp. 33 y 154-162.

${ }^{46}$ Chernilo (2017), p. 13.

${ }^{47}$ Ibid., p. 14.

${ }^{48}$ Braidotti (2013), pp. 13-30.

${ }^{49}$ Chernilo (2017), p. 14.

${ }^{50}$ Ibid., p. 14 (itálicas en el original). Revisar también Davies (2008 [1997]).

${ }^{51}$ Presente en Chernilo (2017), p. 15.

52 Ibid., p. 15.

53 Ibid., p. 15.

${ }^{54}$ Ibid., p. 15.

55 Ibid., p. 15.

${ }^{56}$ Ibid., p. 15 (itálicas en el original).

57 Sobre la noción habermasiana de 'contradicción performativa', revisar, por ejemplo: Habermas (1987 [1981]), p. 308; Habermas (2001), pp. 10-11 y 31; Abdel-Nour (2004), pp. 83-87 y 91-92; Jay (1992); Matustik (1989), esp. pp. 143-148, 169 y 172; Morris (1996); Schoolman (2005), pp. 336, 356-358 y 364; Susen (2007), pp. 77 y 98-68; Susen (2015a), pp. 234, 255, 256, 257, 281, 333 y 340.

${ }^{58}$ Revisar Chernilo (2017), p. 16. También Clark (2001) y Clark (2008).

${ }^{59}$ Chernilo (2017), p. 16 (itálicas en el original).

${ }^{60}$ Ibid., p. 16. Cf. Clark (2008), p. 30.

${ }^{61}$ Clark (2008), p. 75. Revisar Chernilo (2017), p. $17 .^{62}$ Chernilo (2017), p. 17.

${ }^{62}$ Chernilo (2017), p. 17.

${ }^{63}$ Ibid., p. 17 (itálicas en el original, excepto para el artículo del 'antes' de lo artificial).

${ }^{64}$ Ibid., p. 17.

${ }^{65}$ Clark (2008), p. 123 (itálicas en el original). Revisar Chernilo (2017), p. 17.

${ }^{66}$ Revisar Chernilo (2017), p. 18.

${ }^{67}$ Ibid., pp. 229-236.

${ }^{68}$ Por ejemplo, Scheler (2009 [1928]).

${ }^{69}$ Adicionalmente, Cassirer (1972 [1923/1925/1929]).

${ }^{70}$ Revisar, Plessner (1970 [1941]).

${ }^{71}$ Ver Chernilo (2017), p. 229.

72 Ibid., p. 229.

${ }^{73}$ Ibid., p. 229 (itálicas añadidas).

${ }^{74}$ Ibid., p. 229 (itálicas añadidas).

75 Ibid., p. 229.

${ }^{76}$ Ibid., p. 229 (itálicas en el original).

${ }^{77}$ Revisar ibid., pp. 229-236.

${ }^{78}$ Revisar ibid., pp. 229-236.

${ }^{79}$ Ibid., p. 230.

${ }^{80}$ Ibid., p. 230 (itálicas en el original).

${ }^{81}$ Revisar, por ejemplo: Arendt (1967 [1951]); Arendt (1953); Arendt (1998 [1958]); Arendt (2005).

${ }^{82}$ Chernilo (2017), p. 230 (itálicas en el original). 
${ }^{83}$ Ibid., p. 230.

${ }^{84}$ Ibid., p. 230.

${ }^{85}$ Revisar ibid., pp. 230-231.

${ }^{86}$ Sorprendentemente, Chernilo no menciona, dejando de lado su base en, Azmanova (2012).

${ }^{87}$ Chernilo (2017), p. 230.

${ }^{88}$ Ibid., p. 230.

${ }^{89}$ Ibid., p. 230 (itálicas en el original).

90 Ibid., p. 230

91 Ibid., p. 231.

92 Ibid., pp. 231-233.

93 Ibid., p. 231.

94 Ibid., p. 231. Cf. Marx (2000/1977 [1845]), Marx (2000/1977 [1859]), y Marx y Engels (2000/1977 [1846]).

95 Chernilo (2017), p. 231 (itálicas en el original). Cf. Blumenberg (2006).

${ }^{96}$ Chernilo (2017), p. 232. Cf. Voegelin (1962).

97 Ver Chernilo (2017), p. 232. Cf. Blumenberg (2006).

${ }^{98}$ Chernilo (2017), p. 232.

99 Ibid., p. 232 (itálicas en el original).

100 Ver ibid., pp. 233-234.

${ }^{101}$ Ibid., p. 233.

102 Ibid., p. 233.

103 Ibid., p. 233.

104 Ibid., p. 234.

105 Revisar ibid., pp. 234-236.

106 Revisar, por ejemplo: Husserl (1972 [1939]); Husserl (1973 [1939]); Husserl (2012 [1913/1931]).

107 Chernilo (2017), p. 234.

108 Ibid., p. 234.

${ }^{109}$ Ibid., p. 234

110 Ibid., p. 234

${ }^{111}$ Ibid., p. 234

112 Ibid., p. 234.

113 See ibid., pp. 234-235.

${ }^{114}$ Ibid., p. 235.

115 Ibid., p. 236 (itálicas en el original).

${ }^{116}$ Sobre este tema, revisar, por ejemplo: Susen (2009), pp. 91-93, 94-95 y 107-108; Susen (2015a), pp. 76-77, 81-82 y 87; Susen (2017c), pp. 363-363.

117 Susen (2015a), p. 82.

118 Chernilo (2017), p. 17

119 Ibid., p. 17 (itálicas añadidas).

${ }^{120}$ Revisar ibid., p. 21.

${ }^{121}$ Ibid., p. 21 (itálicas añadidas).

${ }^{122}$ Sobre el uso de estos (y otros) criterios en un análisis distinto, revisar Susen (2015a), pp. 23-31.

${ }^{123}$ Chernilo (2017), p. 1.

${ }^{124}$ Sobre este punto, revisar, por ejemplo: Habermas (2001 [1984]), esp. 94-99; Habermas (2001), 13, 44, 45 y 79; Habermas (2018 [2009]), esp. pp. 88, 96, 102, 103, 117, 120 y 156; Susen (2007), pp. 88-89, 114, 244, 251,265 y 286. 
125 Sobre este asunto, revisar: Habermas (2001 [1984]), esp. 94-99; Habermas (2001), 13, 44, 45 y 79; Habermas (2018 [2009]), esp. pp. 88, 96, 102, 103, 117, 120 y 156; Susen (2007), pp. 88-89, 114, 244, 251, 265 y 286.

126 Ibid., p. 4 ( 'y' en cursivas en el original; itálicas añadidas a 'natural' y 'consciente').

127 Revisar, por ejemplo: Boly, Seth, Wilke, Ingmundson, Baars, Laureys, Edelman y Tsuchiya (2013); Lund (2002); Willingham y Riener (2007 [2000]); Wynne (2001); Wynne y Udell (2013 [2001]).

128 Por ejemplo: de Waal (2016); de Waal, Macedo y Ober (2006); Høgh-Olesen (2019); Monsó, Benz-Schwarzburg y Bremhorst (2018); Peterson (2011); Watanabe y Kuczaj (2013).

${ }^{129}$ Chernilo (2017), p. 233 (itálicas añadidas, cita modificada).

130 Ibid., p. 233.

131 Ibid., p. 233.

132 Chernilo (2017), p. 233 (itálicas en el original). Cf. Wilson (2000 [1975]) y Wilson (2004 [1978]).

133 Chernilo (2017), p. 5 (itálicas en el original).

134 Ver, por ejemplo: Bonner y La Farge (1980); de Waal (2001); Durham (1990); Heyes y Galef (1996); Hurley y Chater (2005); Laland y Galef (2009).

135 Sobre el concetpo de 'tipo ideal', revisar, por ejemplo: Haug, Haug y Küttler (2004); Rosenberg (2016); Susen (2015a), pp. 57, 100, 204, 205, 207 y 217.

136 Chernilo (2017), pp. 233-234.

${ }^{137}$ Ver: Colebrook (2010); Fraser, Kember y Lury (2006); Greco (2005); Marks (1998).

138 Chernilo (2017), p. 18.

${ }^{139}$ Ver, por ejemplo: Susen (2013a), p. 228; Susen (2013b), p. 330, 372 y 373.

140 Cf. Joas (1996 [1992]).

${ }^{141}$ Revisar Chernilo (2017), p. 233.

142 Ibid., p. 231 (itálicas en el original).

143 Ibid., p. 231 (itálicas en el original).

144 Ibid., p. 231 (itálicas en el original).

145 Ibid., p. 231 (itálicas en el original). Cf. Blumenberg (2006).

146 Chernilo (2017), p. 7 (itálicas en el original); revisar también ibid., p. 9. Cf. Dahrendorf (1968 [1965]), p. 78.

147 Chernilo (2017), p. 231 (itálicas en el original).

148 Revisar ibid., p. 230.

149 Revisar ibid., p. 230.

150 Susen (2015a), p. 61. Sobre este asunto, revisar también Susen (2007), pp. 164-165, y Susen (2013b), p. 224.

${ }^{151}$ Chernilo (2017), p. 230.

152 Sobre estos asuntos, revisar, por ejemplo: Susen (2013b), p. 224; Susen (2012b), pp. 714-715; Susen (2015a), pp. 54-55.

${ }^{153}$ Chernilo (2017), p. 1 (itálicas en el original).

154 Sobre el concepto de 'metanarrativa' revisar, por ejemplo: Susen (2015a), esp. Capítulo 4. Revisar también Susen (2016d) y Susen (2017b).

155 Chernilo (2017), p. 1 (itálicas añadidas).

156 Ibid., p. 229.

157 Ibid., p. 4 (itálicas en el original).

158 Ibid., p. $4 .{ }^{159}$ Ver Susen (2013a) y Susen (2013b).

${ }^{160}$ Ver Susen (2018a) y Susen (2018b).

161 Cf. Susen (2018a), esp. pp. 1281-1282.

162 Chernilo (2017), p. 6 (itálicas añadidas).

163 Revisar ibid., pp. 7-10. También, por ejemplo: Dahrendorf (1965); Dahrendorf (1968 [1965]); Dahrendorf (1968), ver esp. su ensayo sobre 'La sociología y la naturaleza humana'.

164 Chernilo (2017), p. 8. 
165 Dahrendorf (1968 [1965]), p. 94 . Ver Chernilo (2017), p. 8.

166 Ver Chernilo (2017), pp. 7-10.

167 Ibid., p. 8.

168 Revisar ibid., pp. 7-10.

169 Ibid., p. 8.

170 Ibid., p. 8.

${ }^{171}$ Ibid., p. 8 (itálicas añadidas).

172 Ibid., p. 9 (itálicas en el original).

173 Ibid., p. 9 (itálicas en el original).

174 Ibid., p. 10.

175 Ibid., p. 10.

176 Ibid., p. 10.

177 Ibid., p. 10.

178 Ibid., p. 10.

179 Sobre este asunto, revisar: Bourdieu (1992); Bourdieu y Wacquant (1992); Bourdieu (2013 [1978]). También, por ejemplo: Addi (2001); Collins (1998); Grenfell (2010); Hanks (2005); Honneth (1986 [1984]); Jenkins (1994); Ledeneva (1994); Susen (2013a); Susen (2013b); Wacquant (2002 [1993]); Wacquant (2013).

${ }^{180}$ Sobre este asunto, revisar, por ejemplo: Susen (2007), pp. 174, 241 y 252; Susen (2011a), pp. 450, 453 y 460 ; Susen (2013a), pp. 225-226 y 228; Susen (2014 [2015]), pp. 330-331; Susen (2016c), p. 221.

${ }^{181}$ Sobre este asunto, revisar, por ejemplo: Susen (2007), esp. Capítulo 7 y Capítulo 8; Susen (2011b), p. 181; Susen (2011c), p. 68, 70 y 74; Susen (2013a), esp. pp. 210, 214-218, 222, 226 y 229; Susen (2014); Susen (2016a); Susen (2016c), pp. 202, 210-212, 217 y 222.

182 Ver Susen y Turner (2011).

183 Ver Susen y Turner (2014). También Susen (2012b) y Susen (2015b) así como Susen (2014 [2012]) y Susen (2014 [2015]).

${ }^{184}$ Chernilo (2017), p. 10.

185 Sobre este asunto, revisar Susen (2007), esp. pp. 221-226.

186 Cf. Foucault (2002 [1966/1970]).

187 Chernilo (2017), p. 11.

188 Ibid., p. 15 (itálicas en el original).

189 Ibid., p. 232.

190 Ibid., p. 1 (itálicas añadidas).

${ }^{191}$ Ibid., p. 230 (itálicas en el original).

192 Ibid., p. 230.

193 Cf. Pinker (2002), Pinker (2011) y Pinker (2018).

194 Sobre este asunto, revisar, por ejemplo: Holloway y Susen (2013), p. 33; Susen (2007), pp. 13, 121-125, 226, 260, 261, 268 y 308; Susen (2012a), pp. 296, 306, 309, 311, 312, 319n84, 319n85, 323n148 y 324325n165; Susen (2016b), pp. 74-75; Susen (2013a), pp. 229-230; Susen (2013b), pp. 327, 329, 343, 354, 372 y 373; Susen (2016e), p. 137. 


\section{Referencias}

Abdel-Nour, Farid (2004) "Farewell to Justification: Habermas, Human

Rights and Universalist Morality", Philosophy \& Social Criticism 30(1): 73-96.

Addi, Lahouari (2001) "Violence symbolique et statut du politique chez Bourdieu", Revue française de science politique 51(6): 949-964.

Adorno, Theodor W. (2000 (1993)) Introduction to Sociology, edited by Christoph Gödde, trans. Edmund Jephcott, Cambridge: Polity.

Albrow, Martin (1990) Max Weber"s Construction of Social Theory, London: Macmillan Education.

Archer, Margaret S. (2000) Being Human: The Problem of Agency, Cambridge: Cambridge University Press.

Arendt, Hannah (1953) "A Reply", The Review of Politics 15(1): 76-84.

Arendt, Hannah (1967 (1951)) The Origins of Totalitarianism, 3rd Edition,

London: Allen \& Unwin.

Arendt, Hannah (1998 (1958)) The Human Condition, 2nd Edition, Introduction by Margaret Canovan, Chicago, Ill.: University of Chicago Press.

Arendt, Hannah (2005) The Promise of Politics, edited and with an introduction by Jerome Kohn, New York, NY: Schocken Books.

Atanasoski, Neda and Kalindi Vora (2019) Surrogate Humanity: Race,

Robots, and the Politics of Technological Futures, Durham: Duke University Press.

Azmanova, Albena (2012) The Scandal of Reason: A Critical Theory of

Political Judgment, New York: Columbia University Press.

Badmington, Neil (ed.) (2000) Posthumanism, Houndmills: Palgrave. 
Baert, Patrick (2005) "Max Weber"s Interpretative Method", in Patrick Baert, Philosophy of the Social Sciences: Towards Pragmatism, Cambridge: Polity, pp. 37-60.

Benton, Ted (1977) Philosophical Foundations of the Three Sociologies, London: Routledge \& Kegan Paul.

Benton, Ted and Ian Craib (2001) Philosophy of Social Science: The Philosophical Foundations of Social Thought, Basingstoke: Palgrave.

Bhambra, Gurminder K. (2014) Connected Sociologies, London: Bloomsbury Academic.

Blumenberg, Hans (2006) Beschreibung des Menschen, aus dem Nachlass herausgegeben von Manfred Sommer, Frankfurt am Main: Suhrkamp.

Boly, Melanie, Anil Seth, Melanie Wilke, Paul Ingmundson, Bernard Baars, Steven Laureys, David Edelman, and Naotsugu Tsuchiya (2013) ,Consciousness in Humans and Non-Human Animals: Recent Advances and Future Directions", Frontiers in Psychology 4, Article 625: 1-20.

Bonner, John Tyler and Margaret La Farge (1980) The Evolution of Culture in Animals, Princeton: Princeton University Press.

Borsari, Andrea (2009) "Notes on "Philosophical Anthropology" in Germany. An Introduction", Iris. European Journal of Philosophy and Public Debate 1(1): 113-129.

Bourdieu, Pierre (1992) Language and Symbolic Power, edited and introduced by John B. Thompson, translated by Gino Raymond and Matthew Adamson, Cambridge: Polity.

Bourdieu, Pierre (2013 (1978)) "Symbolic Capital and Social Classes (Introduction, Translation, and Notes by Loïc Wacquant)", Journal of Classical Sociology 13(2): 292-302. 
Bourdieu, Pierre and Loïc Wacquant (1992) "Language, Gender, and Symbolic Violence", in Pierre Bourdieu and Loïc Wacquant, An Invitation to Reflexive Sociology, Cambridge: Polity, pp. 140-174.

Braidotti, Rosi (2013) The Posthuman, Cambridge: Polity.

Braidotti, Rosi (2019) Posthuman Knowledge, Cambridge: Polity.

Butler, Judith (1990) Gender Trouble: Feminism and the Subversion of Identity, London: Routledge.

Cassirer, Ernst (1972 (1923/1925/1929)) La philosophie des formes symboliques, 3 tomes : t. I : Le langage (1923) (trad. Ole Hansen Love et Jean Lacoste), t. II : La pensée mythique (1925) (trad. Jean Lacoste), t. III : La phénoménologie de la connaissance (1929) (trad. Claude Fronty), Paris: Minuit.

Chernilo, Daniel (2013) The Natural Law Foundations of Modern Social Theory: A Quest for Universalism, Cambridge: Cambridge University Press.

Chernilo, Daniel (2014) "The Idea of Philosophical Sociology", The British Journal of Sociology 65(2): 338-357.

Chernilo, Daniel (2017) Debating Humanity: Towards a Philosophical Sociology, Cambridge: Cambridge University Press.

Clark, Andy (2001) Mindware: An Introduction to the Philosophy of Cognitive Science, Oxford: Oxford University Press.

Clark, Andy (2008) Supersizing the Mind: Embodiment, Action, and Cognitive Extension, Oxford: Oxford University Press.

Colebrook, Claire (2010) Deleuze and the Meaning of Life, London: Continuum.

Collins, James (1998) "Language, Subjectivity, and Social Dynamics in the Writings of Pierre Bourdieu", American Literacy History 10(4): 725732. 
Cordero, Rodrigo (2017) Crisis and Critique: On the Fragile Foundations of Social Life, London: Routledge.

Dahrendorf, Ralf (1965) Homo Sociologicus. Ein Versuch zur Geschichte, Bedentung und Kritik der Kategorie der sozialen Rolle, Köln: Westdeutscher Verlag.

Dahrendorf, Ralf (1968) Essays in the Theory of Society, Stanford: Stanford University Press.

Dahrendorf, Ralf (1968 (1965)) Homo Sociologicus, London: Routledge \& Kegan Paul.

Davies, Tony (2008 (1997)) Humanism, 2nd Edition, London: Routledge.

de Waal, Frans (2001) The Ape and the Sushi Master: Cultural Reflections by a Primatologist, New York, NY: Basic Books.

de Waal, Frans (2016) Are We Smart Enough to Know How Smart Animals Are?, London: Granta.

de Waal, Frans, Stephen Macedo, and Josiah Ober (2006) Primates and Philosophers: How Morality Evolved, edited and introduced by Stephen Macedo and Josiah Ober, Princeton, N.J.: Princeton University Press.

Durham, William H. (1990) "Advances in Evolutionary Culture Theory", Annual Review of Anthropology 19(1): 187-210.

Durkheim, Émile (1964 (1960)) Essays on Sociology and Philosophy, edited by Kurt H. Wolff, New York: Harper \& Row.

Durkheim, Émile (1982 (1895)) The Rules of Sociological Method, trans. W. D. Halls, First American Edition, New York: Free Press.

Durkheim, Émile (2010 (1951/1953)) Sociology and Philosophy, trans. D. F. Pocock, with an introduction by J. G. Peristiany, London: Routledge. Fischer, Joachim (2009) "Exploring the Core Identity of Philosophical Anthropology through the Works of Max Scheler, Helmuth Plessner, and Arnold Gehlen", Iris. European Journal of Philosophy and Public Debate 1(1): 153-170. 
Foucault, Michel (2002 (1966/1970)) The Order of Things: An Archaeology of the Human Sciences, London: Routledge.

Fraser, Mariam, Sarah Kember, and Celia Lury (eds.) (2006) Inventive Life: Approaches to the New Vitalism, London: SAGE.

Fukuyama, Francis (2002) Our Posthuman Future: Consequences of the Biotechnology Revolution, London: Profile.

Fuller, Steve (2011) Humanity 2.0: What It Means to be Human Past, Present and Future, Basingstoke: Palgrave Macmillan.

Fuller, Steve (2013) Preparing for Life in Humanity 2.0, Basingstoke: Palgrave Macmillan.

Fuller, Steve and Veronika Lipińska (2014) The Proactionary Imperative. A Foundation for Transhumanism, Basingstoke: Palgrave Macmillan.

Gane, Mike (1988) On Durkheim"s Rules of Sociological Method, London: Routledge.

Gebauer, Gunter and Christoph Wulf (2009) "After the "Death of Man": From Philosophical Anthropology to Historical Anthropology", Iris. European Journal of Philosophy and Public Debate 1(1): 171-186.

Giddens, Anthony (1978) Durkheim, Fontana/Collins: London.

Ginsberg, Morris (1968) Essays in Sociology and Social Philosophy, London: Penguin.

Go, Julian (2016) Postcolonial Thought and Social Theory, Oxford: Oxford University Press.

Greco, Monica (2005) "On the Vitality of Vitalism", Theory, Culture \& Society 22(1): 15-27.

Grenfell, Michael (2010) Bourdieu, Language and Linguistics, London: Continuum.

Guhin, Jeffrey (2019) "Debating Humanity: Towards a Philosophical Sociology (Review)", Contemporary Sociology 48(1): 44-46. 
Habermas, Jürgen (1987 (1981)) "Intermediate Reflections: Social Action, Purposive Activity, and Communication", in Jürgen Habermas, The Theory of Communicative Action. Volume 1: Reason and the Rationalization of Society, trans. Thomas McCarthy, Cambridge: Polity, pp. 273-337.

Habermas, Jürgen (1988 (1963)) Theory and Practice, trans. John Viertel, Cambridge: Polity.

Habermas, Jürgen (2001) Kommunikatives Handeln und detranszendentalisierte Vernunft, Stuttgart: Reclam, Ditzingen.

Habermas, Jürgen (2001 (1984)) "Truth and Society: The Discursive Redemption of Factual Claims to Validity", in Jürgen Habermas, On the Pragmatics of Social Interaction: Preliminary Studies in the Theory of Communicative Action, trans. Barbara Fultner, Cambridge: Polity, pp. 85-103.

Habermas, Jürgen (2003 (2001)) The Future of Human Nature, trans. Hella Beister, Max Pensky, and William Rehg, Cambridge: Polity.

Habermas, Jürgen (2018 (2009)) Philosophical Introductions: Five Approaches to Communicative Reason, trans. Ciaran Cronin, English Edition, Cambridge: Polity.

Hanks, William F. (2005) "Pierre Bourdieu and the Practices of Language", Annual Review of Anthropology 34(1): 67-83.

Haug, Frigga, Wolfgang Fritz Haug, and Wolfgang Küttler (2004) "Idealtypus", in Wolfgang Fritz Haug (ed.) Historisch-Kritisches Wörterbuch des Marxismus (Band 6/I), Hamburg: Argument-Verlag, pp. $622-632$.

Hayles, Katherine (1999) How We Became Posthuman: Virtual Bodies in Cybernetics, Literature, and Informatics, Chicago, Ill.: University of Chicago Press. 
Herbrechter, Stefan (2013 (2009)) Posthumanism: A Critical Analysis, London: Bloomsbury Academic.

Heyes, Cecilia M. and Bennett G. Galef (eds.) (1996) Social Learning in Animals. The Roots of Culture, San Diego: Academic.

Høgh-Olesen, Henrik (2019) The Aesthetic Animal, Oxford: Oxford University Press.

Hollis, Martin (2015 (1977)) Models of Man. Philosophical Thoughts on Social Action, Cambridge: Cambridge University Press.

Holloway, John and Simon Susen (2013) "Change the World by Cracking Capitalism? A Critical Encounter between John Holloway and Simon Susen", Sociological Analysis 7(1): 23-42.

Honneth, Axel (1986 (1984)) "The Fragmented World of Symbolic Forms: Reflections on Pierre Bourdieu"s Sociology of Culture", Theory, Culture \& Society 3(3): 55-66.

Honneth, Axel and Hans Joas (1988 (1980)) Social Action and Human Nature, trans. Raymond Meyer, Cambridge: Cambridge University Press.

Hughes, Henry Stuart (1974) Consciousness and Society: The Reorientation of European Social Thought 1890-1930, London: Paladin.

Hurley, Susan and Nick Chater (eds.) (2005) Perspectives on Imitation: From Neuroscience to Social Science, Cambridge, Mass.: MIT Press.

Husserl, Edmund (1972 (1939)) Erfahrung und Urteil: Untersuchungen zur Genealogie der Logik, 4. Auflage, redigiert und herausgegeben von Ludwig Landgrebe, Hamburg: F. Meiner.

Husserl, Edmund (1973 (1939)) Experience and Judgment: Investigations in a Genealogy of Logic, trans. James S. Churchill and Karl Ameriks, revised and edited by Ludwig Landgrebe, London: Routledge \& Kegan Paul. 
Husserl, Edmund (2012 (1913/1931)) Ideas: General Introduction to Pure Phenomenology, trans. W.R. Boyce Gibson, with a new foreword by Dermot Moran, London: Routledge.

Jay, Martin (1992) "The Debate over Performative Contradiction: Habermas versus the Poststructuralists", in Axel Honneth, Thomas McCarthy, Claus Offe, and Albrecht Wellmer (eds.) Philosophical Interventions in the Unfinished Project of Enlightenment, Cambridge, Mass.: MIT Press, pp. 261-279.

Jenkins, Richard (1994) "Language, Culture and Sociology: Pierre Bourdieu in Context", History of the Human Sciences 7(4): 95-104.

Joas, Hans (1996 (1992)) The Creativity of Action, trans. Jeremy Gaines and Paul Keast, Cambridge: Polity.

Laland, Kevin N. and Bennett G. Galef (eds.) (2009) The Question of Animal Culture, Cambridge, Mass.: Harvard University Press.

Latour, Bruno (1990) "Postmodern? No, Simply Amodern! Steps Towards an Anthropology of Science", Studies In History and Philosophy of Science 21(1): 145-171.

Latour, Bruno (1993 (1991)) We Have Never Been Modern, trans. Catherine Porter, New York: Harvester Wheatsheaf.

Latour, Bruno (2005) Reassembling the Social: An Introduction to ActorNetwork-Theory, Oxford: Oxford University Press.

Latour, Bruno (2013 (2012)) An Inquiry into Modes of Existence: An Anthropology of the Moderns, trans. Catherine Porter, Cambridge, Mass.: Harvard University Press.

Ledeneva, Alena V. (1994) "Language as an Instrument of Power in the Works of Pierre Bourdieu", Manchester Sociology Occasional Papers 41 (November), Editor: Peter Halfpenny, Department of Sociology, University of Manchester, 34 pages. 
Löwith, Karl (1993 (1932)) Max Weber and Karl Marx, with a new preface by Bryan S. Turner, London: Routledge.

Lukes, Steven (1973) Émile Durkheim: His Life and Work. A Historical and Critical Study, London: Allen Lane.

Lund, Nick (2002) Animal Cognition, London: Routledge.

MacIntyre, Alasdair C. (1981) After Virtue: A Study in Moral Theory, London: Duckworth.

Mahon, Peter (2017) Posthumanism: A Guide for the Perplexed, London: Bloomsbury Academic.

Manent, Pierre (1998 (1994)) The City of Man, with a foreword by Jean Bethke Elshtain, trans. Marc A. LePain, Princeton, N.J.: Princeton University Press.

Marcuse, Herbert (2000 (1941/1955)) Reason and Revolution: Hegel and the Rise of Social Theory, 2nd Edition, London: Routledge.

Marks, John (1998) Gilles Deleuze: Vitalism and Multiplicity, London: Pluto Press.

Marx, Karl (2000/1977 (1845)) "Theses on Feuerbach", in David McLellan (ed.) Karl Marx: Selected Writings, 2nd Edition, Oxford: Oxford University Press, pp. 171-174.

Marx, Karl (2000/1977 (1859)) "Preface to A Critique of Political Economy", in David McLellan (ed.) Karl Marx: Selected Writings, 2nd Edition, Oxford: Oxford University Press, pp. 424-428.

Marx, Karl and Friedrich Engels (2000/1977 (1846)) "The German Ideology", in David McLellan (ed.) Karl Marx: Selected Writings, 2nd Edition, Oxford: Oxford University Press, pp. 175-208.

Matustik, Martin J. (1989) "Habermas on Communicative Reason and Performative Contradiction", New German Critique 47: 143-172.

Monsó, Susana, Judith Benz-Schwarzburg, and Annika Bremhorst (2018) "Animal Morality: What It Means and Why It Matters", The Journal of Ethics 22(3): 283-310. 
Morris, Martin (1996) "On the Logic of Performative Contradiction: Habermas and the Radical Critique of Reason", The Review of Politics 58(4): 735-760.

Nayar, Pramod K. (2014) Posthumanism, Cambridge: Polity.

Nisbet, Robert A. (1967) The Sociological Tradition, London: Heinemann.

Peterson, Christopher(2018) Monkey Trouble: The Scandal of Posthumanism, New York: Fordham University Press.

Peterson, Dale (2011) The Moral Lives of Animals, New York: Bloomsbury Press.

Pinker, Steven (2002) The Blank Slate. The Modern Denial of Human Nature, London: Allen Lane.

Pinker, Steven (2011) The Better Angels of Our Nature: A History of Violence and Humanity, London: Penguin.

Pinker, Steven (2018) Enlightenment Now: The Case for Reason, Science, Humanism and Progress, London: Allen Lane.

Plessner, Helmuth (1970 (1941)) Laughing and Crying: A Study of the Limits of Human Behavior, trans. James Spencer Churchill and Marjorie Grene, Evanston: Northwestern University Press.

Rehberg, Karl-Siegbert (2009) "Philosophical Anthropology from the End of World War I to the 1940s and in a Current Perspective", Iris. European Journal of Philosophy and Public Debate 1(1): 131-152.

Rosenberg, M Michael (2016) "The Conceptual Articulation of the Reality of Life: Max Weber"s Theoretical Constitution of Sociological Ideal Types", Journal of Classical Sociology 16(1): 84-101.

Scheler, Max (2009 (1928)) The Human Place in the Cosmos, trans. Manfred S. Frings, Introduction by Eugene Kelly, Evanston, Ill.: Northwestern University Press.

Schnädelbach, Herbert (1984 (1983)) Philosophy in Germany 1831-1933, trans. Eric Matthews, Cambridge: Cambridge University Press. 
Schoolman, Morton (2005) "Avoiding "Embarrassment": Aesthetic Reason and Aporetic Critique in Dialectic of Enlightenment", Polity 37(3): $335-364$.

Sloterdijk, Peter (2009) "Rules for the Human Zoo: A Response to the Letter on Humanism", Environment and Planning D: Society and Space 27(1): $12-28$.

Steane, Andrew M. (2018) Science and Humanity. A Humane Philosophy of Science and Religion, First edition. Edition, Oxford: Oxford University Press.

Susen, Simon (2007) The Foundations of the Social: Between Critical Theory and Reflexive Sociology, Oxford: Bardwell Press.

Susen, Simon (2009) "Between Emancipation and Domination: Habermasian Reflections on the Empowerment and Disempowerment of the Human Subject", Pli: The Warwick Journal of Philosophy 20: 80-110.

Susen, Simon (2011a) ,Kritische Gesellschaftstheorie or kritische Gesellschaftspraxis? Robin Celikates, Kritik als soziale Praxis. Gesellschaftliche Selbstverständigung und kritische Theorie (Frankfurt am Main, Campus Verlag, 2009)", Archives Européennes de Sociologie / European Journal of Sociology 52(3): 447-463.

Susen, Simon (2011b) "Bourdieu and Adorno on the Transformation of Culture in Modern Society: Towards a Critical Theory of Cultural Production", in Simon Susen and Bryan S. Turner (eds.) The Legacy of Pierre Bourdieu: Critical Essays, London: Anthem Press, pp. 173-202. Susen, Simon (2011c) "Epistemological Tensions in Bourdieu"s Conception of Social Science", Theory of Science 33(1): 43-82.

Susen, Simon (2012a) "“Open Marxism” against and beyond the "Great Enclosure"? Reflections on How (Not) to Crack Capitalism", Journal of Classical Sociology 12(2): 281-331. 
Susen, Simon (2012b) "Une sociologie pragmatique de la critique est-elle possible? Quelques réflexions sur De la critique de Luc Boltanski", Revue Philosophique de Louvain 110(4): 685-728.

Susen, Simon (2013a) "Bourdieusian Reflections on Language: Unavoidable Conditions of the Real Speech Situation", Social Epistemology 27(3-4): 199-246.

Susen, Simon (2013b) "A Reply to My Critics: The Critical Spirit of Bourdieusian Language", Social Epistemology 27(3-4): 323-393.

Susen, Simon (2014) "Reflections on Ideology: Lessons from Pierre Bourdieu and Luc Boltanski", Thesis Eleven 124(1): 90-113.

Susen, Simon (2014 (2012)) "Is There Such a Thing as a "Pragmatic Sociology of Critique"? Reflections on Luc Boltanski"s On Critique", in Simon Susen and Bryan S. Turner (eds.) The Spirit of Luc Boltanski: Essays on the "Pragmatic Sociology of Critique", trans. Simon Susen, London: Anthem Press, pp. 173-210.

Susen, Simon (2014 (2015)) "Towards a Dialogue Between Pierre Bourdieu"s "Critical Sociology" and Luc Boltanski"s "Pragmatic Sociology of Critique"", in Simon Susen and Bryan S. Turner (eds.) The Spirit of Luc Boltanski: Essays on the "Pragmatic Sociology of Critique", trans. Simon Susen, London: Anthem Press, pp. 313-348.

Susen, Simon (2015a) The "Postmodern Turn" in the Social Sciences, Basingstoke: Palgrave Macmillan.

Susen, Simon (2015b) "Une réconciliation entre Pierre Bourdieu et Luc Boltanski est-elle possible ? Pour un dialogue entre la sociologie critique et la sociologie pragmatique de la critique", in Bruno Frère (ed.) Le tournant de la théorie critique, Paris: Desclée de Brouwer, pp. 151-186.

Susen, Simon (2016a) Pierre Bourdieu et la distinction sociale. Un essai philosophique, Oxford: Peter Lang. 
Susen, Simon (2016b) "The Sociological Challenge of Reflexivity in Bourdieusian Thought", in Derek Robbins (ed.) The Anthem Companion to Pierre Bourdieu, London: Anthem Press, pp. 49-93.

Susen, Simon (2016c) "Towards a Critical Sociology of Dominant Ideologies: An Unexpected Reunion between Pierre Bourdieu and Luc Boltanski", Cultural Sociology 10(2): 195-246.

Susen, Simon (2016d) "Further Reflections on the "Postmodern Turn" in the Social Sciences: A Reply to William Outhwaite", International Journal of Politics, Culture, and Society 29(4): 429-438.

Susen, Simon (2016e) "Reconstructing the Self: A Goffmanian Perspective", in Harry F. Dahms and Eric R. Lybeck (eds.) Reconstructing Social Theory, History and Practice, Book Series: Current Perspectives in Social Theory, Volume 35, Bingley: Emerald, pp. 111-143.

Susen, Simon (2017a) "Between Crisis and Critique: The Fragile Foundations of Social Life à la Rodrigo Cordero", Distinktion: Journal of Social Theory 18(1): 95-124.

Susen, Simon (2017b) "Following the Footprints of the "Postmodern Turn": A Reply to Gregor McLennan", European Journal of Cultural and Political Sociology 4(1): 104-123.

Susen, Simon (2017c) "Remarks on the Nature of Justification: A SocioPragmatic Perspective", in Charlotte Cloutier, Jean-Pascal Gond, and Bernard Leca (eds.) Justification, Evaluation and Critique in the Study of Organizations: Contributions from French Pragmatist Sociology, Book Series: Research in the Sociology of Organizations, Volume 52, Bingley: Emerald, pp. 349-381.

Susen, Simon (2018a) "Language", in Bryan S. Turner, Chang Kyung-Sup, Cynthia F. Epstein, Peter Kivisto, William Outhwaite, and J. Michael Ryan (eds.) The Wiley Blackwell Encyclopedia of Social Theory, Volume III, Chichester: John Wiley \& Sons, pp. 1278-1290. 
Susen, Simon (2018b) "Saussure, Ferdinand de", in Bryan S. Turner, Chang Kyung-Sup, Cynthia F. Epstein, Peter Kivisto, William Outhwaite, and J. Michael Ryan (eds.) The Wiley Blackwell Encyclopedia of Social Theory, Volume V, Chichester: John Wiley \& Sons, pp. 2001-2006.

Susen, Simon and Bryan S. Turner (eds.) (2011) The Legacy of Pierre Bourdieu: Critical Essays, London: Anthem Press.

Susen, Simon and Bryan S. Turner (eds.) (2014) The Spirit of Luc Boltanski: Essays on the "Pragmatic Sociology of Critique", London: Anthem Press. Taylor, Charles (1989) Sources of the Self: The Making of the Modern Identity, Cambridge: Cambridge University Press.

Turner, Bryan S. (1992) Max Weber: From History to Modernity, London: Routledge.

Voegelin, Eric (1962) "World-Empire and the Unity of Mankind", International Affairs (Royal Institute of International Affairs 1944-) 38(2): 170-188.

Wacquant, Loïc (2002 (1993)) "De 1"idéologie à la violence symbolique.

Culture, classe et conscience chez Marx et Bourdieu", in Jean Lojkine (ed.) Les sociologues critiques du capitalisme. En hommage à Pierre Bourdieu, Paris: Collection Actuel Marx Confrontation, Presses Universitaires de France, pp. 25-40.

Wacquant, Loïc (2013) "Symbolic Power and Group-Making: On Pierre Bourdieu"s Reframing of Class", Journal of Classical Sociology 13(2): 274-291.

Walby, Sylvia (2011) The Future of Feminism, Cambridge: Polity.

Watanabe, Shigeru and Stan A. Kuczaj (eds.) (2013) Emotions of Animals and Humans: Comparative Perspectives, Tokyo: Springer.

Weber, Max (1978 (1922)) Economy and Society: An Outline of Interpretive Sociology, edited by Guenther Roth and Claus Wittich, Berkeley: University of California Press. 
Weber, Max (ed.) (1991 (1948)) From Max Weber: Essays in Sociology, translated, edited, and with an introduction by H. H. Gerth and C. Wright Mills, with a new preface by Bryan S. Turner, London: Routledge.

Weber, Max (2001/1930 (1904-05)) "Author"s Introduction", in Max Weber, The Protestant Ethic and the Spirit of Capitalism, trans. Talcott Parsons, London: Routledge, pp. xxviii-xlii.

Whimster, Sam (2001) "Max Weber: Work and Interpretation", in George Ritzer and Barry Smart (eds.) Handbook of Social Theory, London: SAGE, pp. 54-65.

Willingham, Daniel T. and Cedar Riener (2007 (2000)) Cognition: The Thinking Animal, 4th Edition, Cambridge: Cambridge University Press.

Wilson, Edward O. (2000 (1975)) Sociobiology: The New Synthesis, 25th Anniversary Edition, Cambridge, Mass.: Belknap Press of Harvard University Press.

Wilson, Edward O. (2004 (1978)) On Human Nature, 25th Anniversary Edition, Cambridge, Mass.: Harvard University Press.

Wynne, Clive D. L. (2001) Animal Cognition: The Mental Lives of Animals, Basingstoke: Palgrave.

Wynne, Clive D. L. and Monique A. R. Udell (2013 (2001)) Animal Cognition: Evolution, Behavior and Cognition, 2nd Edition, London: Red Globe Press. 